\title{
The Asymmetric Effects of Uncertainty on Macroeconomic Activity ${ }^{*}$
}

\author{
Paul M. Jones and Walter Enders \\ University of Alabama \\ Department of Economics, Finance, and Legal Studies \\ Tuscaloosa, AL 35487-0224
}

\begin{abstract}
We estimate a number of macroeconomic variables as logistic smooth transition autoregressive (LSTAR) processes with uncertainty as the transition variable. Nonlinear estimation allows us to answer several interesting questions left unanswered by a linear model. For a number of important macroeconomic variables, we show (i) a positive shock to uncertainty has a greater effect than a negative shock, and (ii) the effect of the uncertainty shock is highly dependent on the state of the economy. Hence, the usual linear estimates concerning the consequences of uncertainty are underestimated in circumstances such as the recent financial crisis.
\end{abstract}

Keywords: Nonlinear Models, STAR Models, Uncertainty Shocks, Generalized Impulse Responses

JEL Classifications: E32, E44, C32

* The paper benefitted from helpful suggestions from Timo Teräsvirta and Robert Reed. 


\section{Introduction}

The large trough and subsequent, slow recovery from the Great Recession of 2008-2009 has led to a renewed discussion concerning the effect of uncertainty on the macroeconomy. For example, Becker et al. (2010) report, "According to the Michigan Survey of Consumers, 37 percent of households planned to postpone purchases because of uncertainty about jobs and income [...and] recent capital expenditures and near-term plans for new capital investments remain stuck at 35-year lows." Similarly, policy makers have emphasized the potential damaging effects of uncertainty. Consider the Federal Open Market Committee statement in April 2008: "Several [survey] participants reported that uncertainty about the economic outlook was leading firms to defer spending projects until prospects for economic activity became clearer."

Bernanke (1983) was one of the first to theorize that uncertainty shocks could potentially cause recessions by incentivizing firms to delay investment and employment decisions during times of high uncertainty. More recently, Bloom (2009) and Bloom et al. (2012) develop simulation models in which positive uncertainty shocks lead to temporary reductions in investment and employment. Similarly, Gilchrist, Sim, and Zakrajsek (2010) suggest uncertainty shocks raise the cost of capital leading firms to reduce investment. Panousi and Papanikolaou (2011) find that an increase in uncertainty raises managerial risk aversion, and DeMarzo and Sannikov (2006) find increases in uncertainty result in agency problems which reduce the value of employment. Finally, Baker et al. (2012) develop a policy-related uncertainty index and show that the increase in actual policy uncertainty between 2006 and 2011 could lead to as much as a 3.2 percent decline in GDP.

Unlike the aforementioned papers, we pursue Mishkin's (2011) suggestion that the effect of uncertainty on output is not likely to be linear, especially in the presence of a financial 
disruption. He argues that individuals tend to exaggerate the effects of worst-case scenarios and appear to be more risk-averse in downturns than in upturns. Moreover, as in Bloom (2009), Eisner and Strotz (1963), Lucas and Prescott (1971), and Lucas (1981), investment and employment decisions for an individual firm depend on adjustment costs. Relatively small changes in the level of uncertainty may not induce changes in the firm's desired capital stock. However, in the face of a relatively large change in the level of uncertainty, firms are likely to alter their investment decisions as the costs of adjustment become small relative to the costs of inaction. Finally, it takes longer to expand capacity and hire labor than it takes to shut down capacity or lay off workers. ${ }^{1}$ Thus, we anticipate that uncertainty increases are transmitted to the economy faster than uncertainty decreases. The issue is important, because the aforementioned linear measures of the consequences of uncertainty are essentially averages across different states of the economy. We show that the macroeconomic consequences of uncertainty are especially large when uncertainty is already widespread as in the aftermath of the Great Recession.

We estimate the effects of uncertainty on key macroeconomic variables using a nonlinear framework that allows the sign and magnitude of the uncertainty shocks to have asymmetric effects. Although the theory of the firm allowing for a fixed cost of adjustment indicates that investment acts as a threshold process, aggregating across all firms in the macroeconomy suggests that the region of inaction is actually a smooth process. To capture this type of behavior, we employ a LSTAR model consisting of a high-uncertainty and a low-uncertainty regime with a smooth transition between the two. We use our LSTAR model to examine the differential effects of positive and negative uncertainty shocks both before and during the recent financial crisis. Our LSTAR model can produce impulse response functions which answer three important

\footnotetext{
${ }^{1}$ There is another strand of literature that looks at the idea of the irreversibility of investment. See, for example, Arrow (1968), Bertola and Caballero (1994), and Abel and Eberly (1994).
} 
questions: do positive and negative uncertainty shocks have asymmetric effects, do the effects of uncertainty shocks vary over the business cycle, and do the effects of uncertainty shocks vary disproportionately with the size of the shock?

In Section 2, we describe the data, present linear estimates of important macroeconomic variables, and pretest the data for nonlinearities. Section 3 presents our combination of an exponential generalized autoregressive conditional heteroskedastic (EGARCH) model with an LSTAR model in order to capture the types of nonlinearities likely to exist in the data. Section 4 looks at historical decompositions, and Section 5 evaluates the asymmetric effects of uncertainty shocks on output both before and during the recent financial crisis using generalized impulse response functions. Our results show a positive shock to uncertainty is more persistent and has a greater effect than a negative shock to uncertainty. Also, the effect of the uncertainty shock is highly dependent on whether the shock occurs before or during the crisis. In Section 6, we show that the LSTAR specification also captures the responses of a number of other important macroeconomic variables to different measures of uncertainty. Specifically, industrial production, durable goods, employment, consumer credit, bank loans, and bank cash all display a greater response to positive uncertainty shocks than to negative uncertainty shocks. It is interesting that all but one of these variables decreases in response to uncertainty whereas banks increase their cash holdings as uncertainty rises. Section 7 concludes.

\section{Data and Pretesting for Nonlinearity}

\subsection{Data}

There is no consensus of the best measure of uncertainty, so our approach is to use different measures that have appeared in the academic literature. In Section 3, we follow Bloom (2009) and use the variance of the S\&P 500 as our measure of uncertainty. In Section 6 we use 
several alternative uncertainty measures. Bloom's (2009) primary uncertainty measure is an indicator function that equals unity for seventeen important shocks and zero otherwise. Specifically, these seventeen shocks are events when the Hodrick-Prescott (HP) detrended volatility of the S\&P 500 index rises 1.65 standard deviations above its HP mean. ${ }^{2}$ In a sense, this methodology allows only the large positive uncertainty shocks to have macroeconomic consequences. Instead, we estimate the S\&P 500 index as a GARCH process and use the estimated conditional variance as our uncertainty measure. This allows all uncertainty shocks (regardless of sign and magnitude) to affect the macroeconomy. We also depart from using Bloom's (2009) measure of output. He defines output as the HP detrended log of monthly industrial production. ${ }^{3}$ Instead, to avoid any controversy involved with the use of the HP filter, our output measure is the log difference of monthly industrial production. ${ }^{4}$ All of our data series were obtained from FREDII, and the transformations used for each are described in the Appendix.

\subsection{Pretesting for Nonlinearity}

Before proceeding to estimate each series as a nonlinear process, it seems reasonable to pretest for nonlinearity in order to determine if each series displays some sort of nonlinear adjustment. Toward this end, we subject each series to a battery of tests for nonlinearity. Note that these tests can only suggest whether or not the data generating process is nonlinear and may not be able to pinpoint the proper form of nonlinearity. We employ the following diagnostic tests for nonlinearity:

\footnotetext{
${ }^{2}$ As a robustness check, Bloom (2009) also uses the entire HP detrended volatility series, and the results are virtually unchanged with output declining quickly then overshooting.

${ }^{3}$ Using the HP filter can be problematic. Cogley and Nason (1995) show that the HP filter can generate business cycle dynamics even if none are present in the data. When the data is difference stationary, as in the volatility series of the S\&P 500, the HP filter can amplify growth cycles at business cycle frequencies. Harvey and Jaeger (1993) also show that applying the HP filter can lead to spurious cyclical behavior.

${ }^{4}$ Nevertheless, using the HP filter on our data yields results that are not very different from those reported here.
} 
Pretesting for STAR Models: Teräsvirta (1994) creates a framework to detect the presence of nonlinear behavior using a Taylor series expansion of the general STAR model. This is necessary since it is not possible to directly perform an LM test for the presence of STAR behavior. Consider the following simple LSTAR model:

$$
y_{t}=\alpha_{0}+\alpha_{1} y_{t-1}+\theta\left(\beta_{0}+\beta_{1} y_{t-1}\right)+\varepsilon_{t}
$$

where $\theta=\left[1+\exp \left(-\chi\left(y_{t-1}-c\right)\right)\right]^{-1}$.

The null hypothesis in an LM test for nonlinearity (i.e., $\gamma=0$ ) suffers from the so-called Davies problem since $\beta_{0}, \beta_{1}$, and $c$ are unidentified under the null of $\gamma=0$. Instead, Teräsverta (1994) rewrites $\theta$ as

$$
\theta=\left[1+\exp \left(-\gamma\left(y_{t-1}-c\right)\right)\right]^{-1} \equiv\left[1+\exp \left(-g_{t-1}\right)\right]^{-1},
$$

so $g_{t-1}=\gamma\left(y_{t-1}-c\right)$ and takes a third-order Taylor series approximation of $\theta$ to perform a general test for STAR behavior. The test involves multiplying the regressors in (1) by the approximation for $\theta$ and then regressing all such terms on the residuals of the linear model. Hence, estimate

$$
\varepsilon_{t}=a_{0}+a_{1} y_{t-1}+a_{2} y_{t-2}+a_{11} y_{t-1} y_{t-d}+a_{12} y_{t-2} y_{t-d}+a_{21} y_{t-1} y_{t-d}^{2}+\ldots .
$$

The test for nonlinearity entails the restriction that all values of $a_{i j}=0$.

Regression Error Specification Test (RESET): The Regression Error Specification Test cannot determine the specific form of nonlinearity but assumes the null hypothesis of linearity against a general alternative of nonlinearity. The residuals from a true linear model should not be correlated with the regressors used in the estimating equation or powers of the fitted values. Therefore, a regression of the residuals on powers, the fitted values, and the regressors should have little explanatory power if the model is linear. 
Testing for Threshold Effects: Hansen (1997) develops a supremum test to check for threshold effects and shows how to obtain the appropriate critical values using a bootstrapping procedure. The procedure searches over all possible thresholds to find the best-fitting threshold model. If the $F$ value exceeds the critical value from the bootstrapped $F$ distribution, the null hypothesis of linearity is rejected.

\subsection{Nonlinear Test Results}

Table 1 reports the results from the three nonlinear tests for each of the macroeconomic variables used in our study. ${ }^{5}$ As shown in the table, when we applied Hansen's bootstrap threshold test to industrial production, we obtained an $F$-statistic of 4.72 which is significant at better than the 95 percent level. Notice that each variable has at least two tests allowing us to reject the null hypothesis of linearity at better than the 90 percent confidence level. This suggests that nonlinear models are likely to capture the time series dynamics of these macroeconomic variables more accurately than linear models. However, the particular form of nonlinearity cannot be pinned down by the nonlinear tests. Section 3 discusses our particular nonlinear framework.

\subsection{Testing for EGARCH Behavior in Uncertainty}

Given that our macroeconomic variables should be modeled using a nonlinear framework, we proceed to test our uncertainty measure for nonlinearity. Engle and $\mathrm{Ng}$ (1993) develop a way to determine if positive and negative shocks have different effects on the conditional variance of a series. Let the model of the S\&P 500 have the simple form:

$$
\Delta \ln \left(x_{t}\right)=c+\varepsilon_{1 t}
$$

\footnotetext{
${ }^{5}$ See Section 6 for a complete analysis of additional variables and the Data Appendix for the definitions for the variables.
} 
where $x_{t}$ is the value of the $\mathrm{S} \& \mathrm{P} 500, c$ is a constant, $\varepsilon_{1 t} \sim N\left(0, h_{t}\right)$, and $h_{t}$ is a $\operatorname{GARCH}(1,1)$ process such that the standardized residuals $\left\{s_{t}\right\}$ can be written as

$$
s_{t}=\varepsilon_{1 t} / \sqrt{h_{t}}
$$

Then let $D_{t-1}^{-}$be a dummy variable equal to 1 if $\hat{\varepsilon}_{1 t-1}<0$ and equal to zero if $\hat{\varepsilon}_{1 t-1} \geq 0$. The sign bias test from Engle and $\mathrm{Ng}$ (1993) determines if the $\left\{D_{t-1}^{-}\right\}$sequence can predict the estimated squared residuals. Not only can the sign of the shock affect the conditional variance asymmetrically, but also the size or magnitude of a shock can be asymmetric. To test for asymmetric size effects we conduct a negative (positive) size bias test by regressing $s_{t-1}$ times $D_{t-1}^{-}\left(D_{t-1}^{+}\right)$on the estimated squared residuals.

Table 2 reports the results of Engle and Ng's (1993) tests for asymmetry. The simple GARCH(1,1) model, shown in the first row of the table, is given by $h_{t}=0.00009+$ $0.11 \varepsilon_{t-1}^{2}+0.84 h_{t-1}$. We use the standardized residuals from this model to conduct the tests for asymmetry. A significant coefficient from the sign bias test indicates that positive and negative shocks have different impacts on the conditional variance. Moreover, coefficients from the positive and negative size bias tests are all significant at conventional levels. The $\chi^{2}$-test for the combination of all three tests provides additional evidence supporting the use of an asymmetric EGARCH model. Note that the Akaike Information Criterion (AIC) and the Bayesian Information Criterion (BIC) from the EGARCH model are both smaller than those from the simple GARCH( $(1,1)$ model. Therefore, we estimate the following EGARCH(1,1) model as our measure of uncertainty:

$$
\begin{aligned}
\log h_{t}= & -0.82+0.21\left|\varepsilon_{1 t-1}\right| / \sqrt{h_{t-1}}+0.90 \log h_{t-1}-0.11 \varepsilon_{1 t-1} / \sqrt{h_{t-1}} \\
(-3.02) & (3.48)
\end{aligned}
$$


The key feature of (3) is the negative coefficient on $\varepsilon_{1 t-1} / \sqrt{h_{t-1}}$ which guarantees negative shocks will produce higher variances than similarly sized positive shocks. Panel A of Figure 1 shows the estimated conditional variance of the S\&P 500 index obtained from equation (3) along with monthly U.S. industrial production. Recessions, as defined by the NBER, are represented by shaded areas in Figure 1. While it does appear that positive increases in uncertainty often accompany decreases in output, this is not always the case. The most obvious example is the lack of a significant drop in output following the increase in uncertainty associated with Black Monday, October 19, 1987. This suggests that the effects of an uncertainty shock may depend on the current state of the business cycle at the time of the uncertainty shock.

Our final pretest involves a slight modification to the Teräsverta (1994) procedure described above. In Section 3, we model industrial production as an LSTAR process with our measure of uncertainty, $h_{t}$, as the transition variable. Thus, it is possible to test the null hypothesis of linearity directly against the alternative of an LSTAR model with $h_{t}$ as the transition variable. Consider the following LSTAR model:

$$
y_{t}=\alpha_{0}+\alpha_{1} y_{t-1}+\theta\left(\beta_{0}+\beta_{1} y_{t-1}\right)+\varepsilon_{t}
$$

where $\theta=\left[1+\exp \left(-\chi\left(h_{t}-c\right)\right)\right]^{-1}$ and $h_{t}$ is the measure of uncertainty from (3). Rewrite $\theta$ as

$$
\theta=\left[1+\exp \left(-\gamma\left(h_{t}-c\right)\right)\right]^{-1} \equiv\left[1+\exp \left(-g_{t-1}\right)\right]^{-1}
$$

so $g_{t-1}=\gamma\left(h_{t}-c\right)$ and take a third-order Taylor series approximation of $\theta$ to perform the test for STAR behavior. Our modified Teräsverta (1994) procedure involves multiplying the regressors in (4) by our new approximation for $\theta$ and then regressing all such terms on the residuals of the linear model. The test for nonlinearity entails the restriction that all values of the Taylor series approximation are equal to zero. After carrying out this procedure, we obtain an $F$-statistic of 
3.92 which is significant at better than the 99 percent level. Thus, we reject the null hypothesis of linearity and accept the alternative nonlinear model discussed more fully in Section 3.

\section{The Nonlinear Model of Industrial Production}

In this section, we follow Bloom (2009) and focus on the effect of uncertainty on industrial production. The other important macroeconomic variables listed in Table 1 are analyzed in Section 6. To begin Section 3, we compare a linear model of the industrial production series to our nonlinear specification. For the linear model, the BIC selects a model with two lags. ${ }^{6}$ Let $y_{t}$ denote the logarithmic change in monthly industrial production so that:

$$
y_{t}=0.0013+0.36 y_{t-1}+0.12 y_{t-2}+\varepsilon_{2 t}
$$

$$
\text { aic }=-2129.1 \quad \text { bic }=-2115.3
$$

where $\varepsilon_{2 t}$ denotes the error term for the $\left\{y_{t}\right\}$ process.

The Ljung-Box $Q$-statistics indicate that the residuals are serially uncorrelated. For example, the $Q$-statistics using the first 4 and 8 lags of the standardized residual autocorrelations have prob-values of 0.21 and 0.25 , respectively. The linear model represented by (5) indicates that the $\left\{y_{t}\right\}$ series is not especially persistent; the two characteristic roots are approximately -0.21 and 0.57 . More importantly, the model implies that adjustment is symmetric in the sense that mean reversion is invariant to the sign and magnitude of the discrepancy of $y_{t}$ from its mean. Hence, linearity implies that the phase of the business cycle is irrelevant.

In order to allow uncertainty shocks to have differential effects on industrial production, we also estimate the $\left\{y_{t}\right\}$ series as an LSTAR process. The central feature of the LSTAR specification is the ability to model high and low uncertainty regimes with a smooth transition between the two. Moreover, the LSTAR model nests a threshold process; if, in equation (4), $\gamma$ is

\footnotetext{
${ }^{6}$ We calculate the AIC and BIC as $T \ln (s s r)+2 r$ and $T \ln (s s r)+r \ln (T)$, respectively, where $r$ is the number of estimated parameters and $s s r$ is the sum of squared residuals..
} 
sufficiently large, the LSTAR and threshold specifications are essentially identical. Consider the following LSTAR model of industrial production: ${ }^{7,8}$

$$
\begin{aligned}
& \hat{y}_{t}=0.003+0.28 y_{t-1}+\left(-0.005+0.35 y_{t-1}\right)\left[1+\exp \left(-6.146\left(h_{t}-2.155\right)\right)\right]^{-1} \\
& \quad \begin{array}{lll}
(7.13) \quad(8.26) \quad(-5.97) \quad(5.61) \\
\text { aic }= & -2145.7 \text { bic }= & -2118.1
\end{array}
\end{aligned}
$$

where $\hat{y}_{t}$ denotes the fitted values of the $\left\{y_{t}\right\}$ process.

Notice the transition variable in (6) is the contemporaneous value of uncertainty from (3) as opposed to the lagged value of industrial production. Also note, the AIC and BIC from the LSTAR model are both smaller than the AIC and BIC from the linear model even though the LSTAR model estimates three additional parameters. Panel B of Figure 1 shows the values of $\theta=\left[1+\exp \left(-6.146\left(h_{t}-2.155\right)\right)\right]^{-1}$ plotted as a function of $h_{t}$. In comparing the two panels of

Figure 1, note that $c=2.155$ is close to the center of the estimated $h_{t}$ series and that the transition between regimes is reasonably sharp.

If you examine the skeleton of equation (6), it should be clear that when $\theta=0$ (i.e., when uncertainty is low), the long-run equilibrium of output growth is positive, and the coefficient on $y_{t-1}$ is equal to 0.28 . However, when $\theta=1$ (i.e., uncertainty is high), the long-run equilibrium of output growth is negative, and the coefficient on $y_{t-1}$ is 0.63 (i.e., $0.28+0.35=0.63$ ). Therefore, high values of uncertainty decrease output and are more persistent than low values of uncertainty.

\section{Historical Decompositions}

\footnotetext{
${ }^{7}$ See Section 5.2 for analysis using a nonlinear VAR model and Section 6 for model estimates of other important macroeconomic measures and different measures of uncertainty.

${ }^{8} \mathrm{~A} t$-test for $\gamma$ is not reported since the parameters in the LSTAR model are undefined when $\gamma=0$. Likewise, the variance is always positive. Therefore, a $t$-test for $c=0$ is also not reported.
} 
In order to highlight the effects of uncertainty on output, we perform two counterfactual analyses; one for the 2000:M1-2012:M1 period and the other for the 2009:M6-2012:M1 period. For the 2000:M1-2012:M1 period, we fix the value of uncertainty equal to the average value over the 1990s. Therefore, the $h_{t}$ series is set equal to 1.48 and $\theta \approx 0.015$ for each time period. Then, we set the initial condition for $y_{t}$ equal to the actual value of industrial production growth for 2000:M1 and iterate forward. Panel A of Figure 2 shows the recursive counterfactual values of industrial production compared to the actual values. ${ }^{9}$ Clearly, if the uncertainty values for the 1990s had continued, we would have expected strong output growth. Specifically, the level of industrial production at the end of the twelve-year period is estimated to be almost 70 percent higher than the actual value.

Panel B of Figure 2 shows the time series plot of actual and counterfactual industrial production for the second historical decomposition, 2009:M6-2012:M1. For this decomposition we set $h_{t}$ equal to the average value of uncertainty during the recent financial crisis (i.e., $h_{t}$ is fixed at 4.98 so that $\theta \approx 1$ ). Then we set the initial condition $y_{t}$ equal to the actual value for 2009:M6 and iterate forward. As shown in the figure, if the uncertainty level had remained constant at its average level for the financial crisis, output would have continued to decline sharply. Note that over the 2009:M6-2012:M1 period, counterfactual industrial production would have fallen by more than 20 percent as compared to the actual value.

\section{Impulse Response Functions}

Koop, Pesaran, and Potter (1996) develop a framework for estimating impulse responses from nonlinear models. Traditional impulse response functions have a symmetry property (e.g., a shock of -1 has exactly the opposite effect of a shock of +1 ) and a linearity property (e.g., a

\footnotetext{
${ }^{9}$ Note that for our counterfactual analyses and generalized impulse responses we sum the changes in output growth in order to obtain the estimated levels of industrial production.
} 
shock of size 2 has exactly twice the effect of a shock of size 1). However, the interpretation of impulse response functions for a nonlinear model is not as straightforward, since the initial state of the system, as well as the size, sign, and subsequent values of the shocks, affect the responses.

To calculate generalized impulse responses, we specify the history of the system and the value of the uncertainty shock. Then, we select randomly drawn realizations of the residuals from (2) to produce $\varepsilon_{1 t+1}^{*}, \varepsilon_{1 t+2}^{*}, \ldots, \varepsilon_{1++24}^{*}$. Because the residuals may not have a normal distribution, we select the residuals using standard bootstrapping procedures. In particular, we draw with replacement the residuals from a uniform distribution and use these residuals to produce $\left\{h_{t}^{*}\right\}=$ $h_{t}^{*}$ through $h_{t+24}^{*}$. These $\left\{h_{t}^{*}\right\}$ values are substituted into the LSTAR model given by (6) to generate the recursive values of $y_{t}^{*}$ through $y_{t+24}^{*}$. For each particular history, we repeat the process 1000 times and obtain the mean values of the impulse responses along with the 95 percent confidence intervals.

\subsection{Generalized Impulse Response Results}

Panel $\mathrm{C}$ of Figure 2 shows the impulse responses of a permanent positive and negative uncertainty shock on output. We initialize the model in period one by setting the magnitude of uncertainty equal to the centrality parameter $c$ and the $\log$ difference of industrial production equal to its long-run equilibrium from the linear model, equation (5). Thus, $\theta=1 / 2$ in period one before the uncertainty shocks and industrial production is equal to $0.013 /(1-0.36-0.12)=$ 0.0025. Note that with the parameterization of the EGARCH model a negative innovation in the residuals leads to a higher conditional variance and is a positive uncertainty shock. The uncertainty shocks in Panel $\mathrm{C}$ of Figure 2 are permanent positive and negative one-standarddeviation shocks from the residuals of (2). Hence, for a permanent positive (negative) uncertainty shock, the value of uncertainty in every period is determined by setting the residuals 
$\varepsilon_{1 t+1}^{*}, \varepsilon_{1 t+2}^{*}, \ldots, \varepsilon_{1 t+12}^{*}$ equal to a minus (plus) one-standard-deviation innovation in the residuals of (2). As shown by the reflection of the permanent positive uncertainty shock in Panel C of Figure 2 , increases in uncertainty have larger effects on output than decreases in uncertainty. Specifically, industrial production falls from 0.0025 to -0.0054 for the permanent positive uncertainty shock and rises only from 0.0025 to 0.00417 for the permanent negative uncertainty shock. ${ }^{10}$ Also, consistent with our historical decompositions, permanent high values of uncertainty lead to permanent decreases in output, and permanent low values of uncertainty lead to permanent increases in output.

Panel A of Figure 3 shows the effects of a temporary positive, one-standard-deviation shock to uncertainty during the recent financial crisis. Unlike the procedures used to produce Figure 2, here we change only the value of $\varepsilon_{1 t}^{*}$ for 2008:12 and select the subsequent residuals using standard bootstrapping procedures. We repeat this procedure 1000 times. The figure shows the mean values of industrial production along with 95 percent confidence intervals. Initially, a positive one-standard-deviation uncertainty shock causes industrial production to fall. The series returns to its original value in little more than a year.

Panel B of Figure 3 shows how an actual uncertainty shock from the midst of the financial crisis (2008:12) would have affected output if it had occurred in 2008:1 (i.e., before the onset of the crisis). The actual magnitude of the shock is more than twice that used in Panel A of Figure 3. Nevertheless, the effect of the shock on output is small; output continues to rise in spite of the shock. While the 2008:12 uncertainty shock actually had a large negative effect on output for that period, our counterfactual analysis shows that it would have little effect if it had occurred

\footnotetext{
${ }^{10}$ Table 3 reports these same results in a different manner. 0.0025 is the long-run equilibrium from the linear model of industrial production, -0.0054 is the high uncertainty regime equilibrium, and 0.00417 is the low uncertainty regime equilibrium.
} 
when the economy was strong. The key point is that this hypothetical increase in uncertainty occurs when the state of the economy is strong. Therefore, uncertainty shocks occurring during deep recessions such as the recent financial crisis have vastly different effects than the same sized shocks occurring during expansions.

One interesting feature of the LSTAR model is that the consequence of uncertainty shocks need not be homogeneous of degree one in the size of the shock. In Panel A of Figure 4, we investigate how different sized shocks affect industrial production were they all to occur in 2008:12. The solid, dotted, and dashed lines show bootstrapped mean values of $+2,+1$, and -1 standard-deviation temporary shocks on industrial production, respectively. Notice that the uncertainty shocks affect industrial production negatively in each case even when the shock is negative. However, positive uncertainty shocks lead to larger decreases in output and longer recovery times than negative uncertainty shocks. Following a negative one-standard-deviation uncertainty shock, output returns to pre-shock levels after approximately 12 months. After a positive one-standard-deviation shock, output recovers after approximately 18 months, and after a positive two-standard-deviation shock, output returns to pre-shock levels in approximately 24 months.

Panel B of Figure 4 shows the results of repeating the exercise assuming that the same sized shocks occurred on 2008:1. In this case, the temporary uncertainty shocks barely affect output. Even large positive uncertainty shocks do not affect output substantially. The point is that reasonably sized uncertainty shocks — even as much as two-standard-deviations—occurring during a favorable state of economic activity have little effect. 5.2 An Alternative Methodology 
An alternative methodology to estimate the nonlinear effects of uncertainty on output is to estimate the growth rate of industrial production (i.e., $y_{t}$ ) and uncertainty as a simultaneous system. Since the conditional variance of the S\&P 500 is not directly observable, we use implied volatility based on the Chicago Board of Options Exchange VXO index as our measure of uncertainty. This index is available from 1986 onward. Using this methodology we are able to shed light on the following question of causality: Does an increase in uncertainty cause output to drop or does a decrease in output cause uncertainty to increase? We continue to estimate $y_{t}$ as an LSTAR process and estimate the VXO as an equation in a vector autoregression (VAR).

Consider the following estimation:

$$
\begin{aligned}
& y_{t}=0.0033-0.15 y_{t-1}+\left(-0.0039+0.76 y_{t-1}\right)\left[1+\exp \left(-4.36\left(v x o_{t-1}-23.23\right)\right)\right]^{-1}+\varepsilon_{3 t} . \\
& \begin{array}{lll}
(6.93) \quad(-1.80) & (-5.20) & (6.62)
\end{array} \\
& v x o_{t}=3.55+0.83 v x o_{t-1}+30.45 y_{t-1}+\varepsilon_{4 t} .
\end{aligned}
$$

All of the estimates in the nonlinear system are obtained simultaneously using nonlinear least squares. Once again, the transition variable in the LSTAR model of output is the lagged value of the VXO index as opposed to lagged values of output. Notice in the equation for uncertainty the coefficient on output is insignificant. In a sense the $t$-statistic in this case acts like a Granger causality test. Thus, an insignificant coefficient suggests that output is not driving uncertainty, but in fact changes in uncertainty are causing changes in output.

Figure 5 plots the values of $\theta$ against our uncertainty measure where $\theta=\left[1+\exp \left(-4.36\left(v x o_{t-1}-23.23\right)\right)\right]^{-1}$. The figure shows high values of uncertainty produce $\theta$ values equal to one, low values of uncertainty produce $\theta$ values equal to zero, and intermediate values of uncertainty produce $\theta$ values between zero and one. When $\theta=0$ and uncertainty is 
low, the long-run equilibrium of output is positive, and the coefficient on $y_{t-1}$ is equal to -0.15 . However, when $\theta=1$ and uncertainty is high, the long-run equilibrium of output is negative, and the coefficient on $y_{t-1}$ is 0.61 . Therefore, consistent with our two-step estimation, high values of uncertainty decrease output and are more persistent than low values of uncertainty.

\section{Alternative Measures of Uncertainty and Other Important Macroeconomic Variables}

To determine whether uncertainty shocks induce asymmetric responses in other sectors, we investigate the effects of uncertainty on a number of other important macroeconomic variables. Moreover, to ensure that the results are robust, we examine the effects of several uncertainty measures. The results are presented in Table 4 . In each case, uncertainty is the transition variable in the most appropriate LSTAR model for each sector. As should be clear from (1), $\beta_{0}$ is a measure of the effect of high values of uncertainty on each of the macroeconomic variables. Interestingly, all of the coefficient estimates of $\beta_{0}$ are negative except for the last regression. This means that high values of uncertainty cause a drop in every important macroeconomic variable except bank cash which increases during times of high uncertainty. In other words, an increase in uncertainty decreases production and financial flows, but increases the amount of cash that banks choose to hold. This also provides evidence for the direction of causality between uncertainty and output. If the change in output is causing uncertainty to change, it is unlikely that uncertainty would affect each production and financial flow variable similarly.

Since the value of $\beta_{1}$ can also affect the long-run equilibrium, Table 3 examines the skeleton of each model to determine the long-run equilibrium for each regime. The high uncertainty regime equilibrium is calculated by setting $\theta=1$ and the low uncertainty regime 
equilibrium is found by setting $\theta=0$ in each of the LSTAR models reported in Table 4 . For example, the last column of Table 4 reports estimates for the LSTAR model of bank cash with the spread between the 30-year corporate junk bond and the 30 -year treasury bond as the measure of uncertainty. When $\theta=1$, the sum of the intercept terms equals $0.004+0.04=0.044$, and the sum of the autoregressive coefficients equals $-0.007+0.62=0.613$. Therefore, the high uncertainty regime equilibrium is $0.044 /(1-0.613)=0.1137$. The difference between the high uncertainty regime equilibrium and the long-run equilibrium from the linear model is 0.1137 $0.00632=0.10738$. Notice that the absolute values of the difference between the high uncertainty regime equilibrium and the long-run equilibrium from the linear model are greater than the differences between the low uncertainty regime and the long-run equilibrium in every case except one. The exception is when our uncertainty measure is Business Outlook Survey (BOS) data and our macroeconomic variable is consumer credit. Often the effects of positive uncertainty shocks are several times larger than negative uncertainty shocks. ${ }^{11}$ Therefore, we conclude that positive uncertainty shocks have larger effects than negative uncertainty shocks across a number of important macroeconomic variables and various measures of uncertainty.

\section{1 - The Asymmetric Effects of Uncertainty on Consumer Credit}

Given the recent claims that banks have been hoarding cash and frustrating the Federal Reserve's efforts to lower interest rates, we examine the effects of uncertainty shocks on consumer credit in more detail. Specifically, we look at how the conditional variance of the S\&P 500 index affects consumer credit. The best-fitting model of consumer credit is:

$$
\begin{gathered}
\hat{y}_{t}=0.0031+0.61 y_{t-1}+\left(-0.0026+0.08 y_{t-1}\right)\left[1+\exp \left(-3.23\left(h_{t}-2.103\right)\right)\right]^{-1} \\
\left(\begin{array}{llll}
(6.66) & (20.87) & (-3.52) & (1.02)
\end{array}\right.
\end{gathered}
$$

\footnotetext{
${ }^{11}$ This can be seen graphically in Figure 2 Panel C and Figure 7 Panel C.
} 
where $y_{t}$ denotes the growth rate of consumer credit.

Panel A of Figure 6 shows monthly U.S. consumer credit along with the conditional variance of the S\&P 500 index estimated by an $\operatorname{EGARCH}(1,1)$ model. Recessions, as defined by the NBER, are represented by shaded areas of the figure. On inspection, consumer credit growth seems to decline with the onset of a recession. In Panel B of Figure 6, we show the values of $\theta$ against the estimated values of $h_{\mathrm{t}}$. The centrality parameter $c=2.103$ is near the center of the estimated $h_{t}$ series shown in Panel A. When uncertainty is low (i.e., $\theta$ is close to zero), the skeleton of (6) indicates that the long-run equilibrium value of consumer credit is $0.00795=$ $0.0031 /(1-0.61)$. However, when uncertainty is high (i.e., $\theta$ is close to unity), the long-run equilibrium of consumer credit is only $0.00161=(0.0031-0.0026) /(1-0.61-0.08)$. Therefore, consumer credit slows considerably during times of high uncertainty.

\section{2 - Historical Decomposition}

We perform two counterfactual analyses to show the effects of uncertainty on consumer credit; one for 2000:M1-2012:M1 and the other for 2010:M6-2012:M6. The historical decomposition for 2000:M1 - 2012:M1 is shown in Panel A of Figure 7. Similar to our aforementioned historical decompositions, during this first period we set the value of uncertainty equal to its average value of for the 1990 s (i.e., $h_{t}=1.48$ and $\theta \approx 0.015$ in each time period). Then we set the initial condition for $y_{t}$ equal to the actual value of consumer credit growth for 2000:M1 and iterate forward. Panel A of Figure 7 shows the recursive counterfactual values of consumer credit compared to the actual values. Clearly, if the average level of uncertainty values for the 1990s had continued, we would have expected strong growth in consumer credit. Specifically, the level of consumer credit at the end of the twelve-year period is estimated to be almost 90 percent higher than the actual value. 
Panel B of Figure 7 shows the time series plot of consumer credit for the second historical decomposition, 2010:M6-2012:M6. We set the value of uncertainty equal to its average during the recent financial crisis (i.e., $h_{t}$ is fixed at 4.98 so that $\theta \approx 1$ ). Then we set the initial condition $y_{t}$ equal to the actual value for 2010:M6 and iterate forward. As shown in Figure 7, if the uncertainty level had remained constant at its average level for the financial crisis, consumer credit would have grown at a slower rate. Note that over the two year period counterfactual consumer credit would have been approximately 5 percent lower than actual consumer credit. The fact that the differential between the actual and counterfactual values is relatively small compared to other sectors reflects the tendency of banks to hoard cash. As shown in the last column of Table 4, high uncertainty increases the intercept of bank cash holdings from 0.004 to 0.044 and the persistence parameter from -0.007 to 0.613 . Therefore, even in the absence of additional positive uncertainty shocks, the increase in the persistence parameter means banks continue to hoard cash and restrict the amount of consumer credit.

\section{3 - Generalized Impulse Responses}

Panel C of Figure 7 shows the impulse responses of a permanent positive and a permanent negative uncertainty shock on consumer credit. We initialize the model in period one by setting the magnitude of uncertainty equal to the centrality parameter $c$ and the log difference of consumer credit equal to its long-run equilibrium from the linear model [i.e., row 4 in Table 3]. Thus, $\theta=1 / 2$ in period one before the uncertainty shocks and consumer credit is equal to 0.00633. For a permanent positive (negative) uncertainty shock, the value of uncertainty in every period is determined by setting the residuals $\varepsilon_{1 t+1}^{*}, \varepsilon_{1 t+2}^{*}, \ldots, \varepsilon_{1 t+12}^{*}$ equal to a minus (plus) onestandard-deviation innovation of the residuals in (2). As illustrated by the reflection of the permanent positive uncertainty shock shown in Panel C of Figure 7, increases in uncertainty 
have larger effects on consumer credit than decreases in uncertainty. Specifically, consumer credit falls from 0.00633 to 0.0016 for the permanent positive uncertainty shock and rises only from 0.0063 to 0.00795 for the permanent negative uncertainty shock.

We investigate how different sized shocks affect consumer credit were they all to occur in 2008:12. In Panel A of Figure 8, the solid, dotted, and dashed lines show bootstrapped mean values of $+2,+1$, and -1-standard-deviation temporary shocks on consumer credit, respectively. Notice that in each case the uncertainty shocks slow consumer credit for the first three months after the shock. Moreover, changing the magnitude of the shock has a non-proportional effect on consumer credit. Although the differential between $\mathrm{a}+1$ and $\mathrm{a}-1$ standard deviation shock is twice that of $\mathrm{a}+1$ to +2 standard deviation shock, the magnitude of the effects on consumer credit is about the same.

Panel B of Figure 8 repeats the exercise assuming that shocks of the same size occurred on 2008:1. In this case, the temporary uncertainty shocks barely affect consumer credit. Even large positive uncertainty shocks do not affect consumer credit substantially. The key point is that the timing of temporary uncertainty shocks matters more than the magnitude of temporary uncertainty shocks.

\section{Conclusion}

We contribute to the growing literature on uncertainty by investigating the asymmetric effects of uncertainty on macroeconomic activity before and during the recent financial crisis. Instead of estimating a conventional linear model, we estimate uncertainty using an EGARCH model to allow positive and negative shocks to have asymmetric effects, and we estimate output using an LSTAR model. We show that increases in uncertainty have greater effects than decreases in uncertainty on a number of important macroeconomic variables. These results are 
robust to several measures of uncertainty and important macroeconomic variables. We also provide two potential answers to the question of the direction of causality. First, we develop a nonlinear VAR model and show that the coefficient on output is insignificant in the equation for uncertainty. Second, uncertainty is shown to affect many different sectors of the economy which is unlikely to be the case if output is truly causing the changes in uncertainty.

Since linear models are essentially averages across the two types of shocks, they underestimate the economic effects of increases in the level of uncertainty. Moreover, the timing of the shocks is also crucial because uncertainty shocks that occur during severe recessions are likely to have much more profound effects than shocks of similar size occurring during expansions. Our findings suggest policy makers should be especially concerned about minimizing the level of uncertainty during downturns such as the recent financial crisis.

Although we find unidirectional causality between uncertainty and the key macroeconomic variables, there may be unobservable business cycle phenomena that simultaneously affect both uncertainty and the macroeconomic variables. Nevertheless, the asymmetric pattern we find is consistent across industrial production, durable good production, employment, consumer credit, bank loans and bank cash. 


\section{Data Appendix}

In this appendix, we describe the data for our measures of uncertainty and macroeconomic variables.

\section{A.1 - Output Data}

We use three different measures of output and three financial measures to investigate the effects of uncertainty. All of the measures come from the Federal Reserve Economic Database (FRED). All variables are found to be difference stationary and

\section{Industrial Production}

Industrial production is the log difference of monthly industrial production from 1950:1-2012:1.

\section{Durable Goods}

Durable goods is the log difference in monthly durable consumer goods taken from industrial production from 1950:1-2012:1.

\section{Employment}

Employment is the log difference in monthly total nonfarm employees from 1950:1-2012:1.

\section{Consumer Credit}

Consumer credit is the log difference in total monthly consumer credit owned and securitized, outstanding from 1950:1-2012:1.

\section{Bank Loans}

Bank loans is the log difference in commercial and industrial loans at all commercial banks from 1950:1-2012:1.

\section{Bank Cash}

Bank cash is the log difference in cash assets at all commercial banks from 1973:1-2012:1.

\section{A.2 - Uncertainty Data}

We use the following four variables as our measures of uncertainty.

\section{Conditional Variance of the S\&P 500}

We use an EGARCH(1,1) model as our estimate of the conditional variance of the S\&P 500 .

\section{Interest Rate Spread}

For our second measure of uncertainty we follow Gilchrist, Sim, and Zakrajsek (2009) and use the spread between the 30-year Baa corporate bond and the 30-year Treasury bond. If the 30-year bond is not available, we use the 20 -year bond.

\section{Business Outlook Survey}

Our next measure comes from Bachmann, Elstner, and Sims (2013). It quantifies disagreements in The Philadelphia FED District Business Outlook Survey (BOS). In particular, we use the 
response of manufacturing firms to the following question from the survey: "What is your evaluation of the level of general business activity six months from now vs. current month: decrease, no change, increase?" We subsequently calculate uncertainty using the following formula:

$$
\begin{aligned}
& \text { uncertainty }_{t}=\operatorname{sqrt}\left(\text { Frac }_{t}(\text { increase })+F r a c_{t}(\text { decrease })-\right. \\
& \left(\text { Frac }_{t}(\text { increase })_{\left.\left.- \text {Incac }_{t}(\text { decrease })\right)^{2}\right)}\right.
\end{aligned}
$$

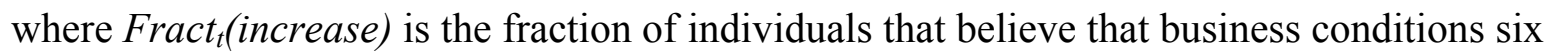
months from time $t$ will increase, and rract $_{t}$ (decrease) is defined similarly.

\section{Uncertainty Index}

Our final measure of uncertainty is the monthly, policy-related uncertainty index by Baker et al. (2012) which spans January 1985 to January 2012 and combines three index components. The first quantifies the number of references to policy-related uncertainty in ten leading newspapers. The next component is the number of federal tax code provisions set to expire in future years, and the final is the extent of disagreement between economic forecasters over future federal government purchases and consumer price index (CPI) levels. 


\section{References:}

Abel, Andrew B. and Janice C. Eberly (1994). “A Unified Model of Investment Under Uncertainty.” American Economic Review, 84, pp. 1369-1384.

Arrow, Kenneth J (1968). "Optimal Capital Policy with Irreversible Investment.” in J.N. Wolfe, ed., Value, capital and growth. Paper in honour of Sir John Hicks. Edinburgh: Edinburgh University Press, pp. 1-19.

Bachmann, R., S. Elstner, and E. Sims (2013). "Uncertainty and Economic Activity: Evidence from Business Survey Data.” American Economic Journal: Macroeconomics, 5, pp. 217-249.

Baker, S., N. Bloom, and S. Davis (2012). "Measuring Economic Policy Uncertainty.” Working Paper. Stanford University.

Becker, Gary S., Steven J. Davis, and Kevin M. Murphy (2010). "Uncertainty and the Slow Recovery: A Recession is a Terrible Time to Make Major Changes in the Economic Rules of the Game." Wall Street Journal. 4 Jan 2010.

Bernanke, Ben (1983). "Irreversibility, Uncertainty, and Cyclical Investment." The Quarterly Journal of Economics, 98, pp. 85-106.

Bertola, Giuseppe and Ricardo J. Caballero (1994). "Irreversibility and Aggregate Investment." Review of Economic Studies, 61, pp. 223-246.

Bloom, Nick. (2009). “The Impact of Uncertainty Shocks.” Econometrica, 77, pp. 623- 685.

Bloom, N., M. Floetotto, and N. Jaimovich (2012). "Really Uncertain Business Cycles.” NBER Working Paper 18245.

Cogley, Timothy and James M. Nason (1995). "Effects of the Hodrick-Prescott Filter on Trend and Difference Stationary Time Series: Implications for Business Cycle Research." Journal of Economic Dynamics and Control, 19, pp. 253-278.

DeMarzo, Peter M. and Uuliy Sannikov (2006). "Optimal Security Design and Dynamic Capital Structure in a Continuous-Time Agency Model." Journal of Finance, 61, pp. 2681-2724.

Eisner, Robert and Robert H. Strotz (1963). "Determinants of Business Investment." in Commission on Money and Credit, Impacts of monetary policy. Englewood Cliffs, NJ: Prentice Hall, pp. 59-337.

Engle, Robert F. and Victor K. Ng (1993). "Measuring and Testing the Impact of News on Volatility." Journal of Finance, 48, pp. 1749-1778.

Federal Open Market Committee (2008). "Minutes of the Federal Open Market Committee." April 29-30, 2008. 
Gilchrist, S., J. Sim, and E. Zakrajsek (2010). "Uncertainty, Financial Frictions, and Investment Dynamics.” Mimeo, Boston University.

Hansen, B. (1997). "Inference in TAR Models." Studies in Nonlinear Dynamics and Econometrics, 1, pp. 119-131.

Harvey, A.C. and A. Jaeger (1993). "Detrending, Stylized Facts and the Business Cycle." Journal of Applied Econometrics, 8, pp. 231-247.

Koop, Gary, M.Hashem Pesaran, and Simon M. Potter (1996). "Impulse Response Analysis in Nonlinear Multivariate Models." Journal of Econometrics, 74, pp. 119-147.

Lucas, Robert E. Jr. (1981). “Optimal Investment with Rational Expectations.” in Robert E. Lucas, Jr., and Thomas J. Sargent, eds., Rational expectations and economic practice, Vol I. Minneapolis: University of Minnesota Press, pp. 55-66.

Lucas, Robert E. Jr. and Edward C. Prescott (1971). "Investment under Uncertainty." Econometrica, 39, pp. 659-681.

McLeod A.I. and W.K. Li (1983). "Diagnostic Checking ARMA Time Series Models Using Squared-Residual Autocorrelations.” Journal of Time Series Analysis, 4, pp. 269-273.

Mishkin, Frederic S. (2011). "Monetary Policy Strategy: Lessons From the Crisis.” NBER Working Paper 16755.

Panousi, Vasia and Papanikolaou, Dimitris (2011). "Investment, Idiosyncratic Risk and Ownership." Journal of Finance, 67, pp. 1113-1148.

Teräsvirta, Timo (1994). "Specification, Estimation, and Evaluation of Smooth Transition Autoregressive Models." Journal of the American Statistical Association, 89, pp. 208-218. 
Table 1 Nonlinearity Tests

\begin{tabular}{|c|c|c|c|c|c|c|}
\hline Nonlinear Tests ${ }^{1}$ & $\begin{array}{l}\text { Industrial } \\
\text { Production }\end{array}$ & $\begin{array}{l}\text { Durable } \\
\text { Goods }\end{array}$ & Employment & $\begin{array}{c}\text { Consumer } \\
\text { Credit }\end{array}$ & Bank Loans & Bank Cash \\
\hline Teräsvirta (1994) & $2.52 * *$ & $18.72 * * *$ & $6.30 * * *$ & 0.85 & $2.93 * * *$ & $8.56^{* * *}$ \\
\hline RESET & $2.15^{*}$ & $18.72^{* * *}$ & 0.91 & $2.08^{*}$ & $3.37^{* *}$ & $14.09 * * *$ \\
\hline Test of Threshold Effect & $4.72 * *$ & $15.10 * * *$ & $12.53 * * *$ & $12.03 * * *$ & $5.32 * * *$ & $5.18 * * *$ \\
\hline
\end{tabular}

Note: The table reports $F$-statistics for each of the above nonlinear tests.

* Denotes statistical significance at the $90 \%$ level.

** Denotes statistical significance at the $95 \%$ level.

*** Denotes statistical significance at the $99 \%$ level.

${ }^{1}$ Under the null hypothesis, each process is linear. 
Table 2 - Testing for EGARCH Behavior in Uncertainty

GARCH(1,1) Model

Engle and $\mathrm{Ng}(1993)$ Tests

Sign Bias Test

Negative Size Bias Test

Positive Size Bias Test

All Three Tests

EGARCH $(1,1)$ Model

$$
\begin{aligned}
& h_{t}=\underset{(2.86) \quad 0.00009+0.11 \varepsilon_{t-1}^{2}+0.84 h_{t-1}}{(4.55)}(29.98) \\
& \text { aic }=-2642.18 \text { bic }=-2623.74
\end{aligned}
$$

$$
s_{t}^{2}=0.71+0.61 D_{t-1}^{-}+v_{t}
$$

$$
\begin{aligned}
S_{t}^{2}= & 0.91-0.23 D_{t-1}^{-} S_{t-1}+v_{t} \\
& (10.65) \quad(-2.10)
\end{aligned}
$$

$$
S_{t}^{2}={ }_{(13.45)}\left(.20-0.55 D_{t-1}^{+} s_{t-1}+v_{t}\right.
$$

$$
s_{t}^{2}=\begin{aligned}
& 0.91+0.51 D_{t-1}^{-}+0.11 D_{t-1}^{-} s_{t-1}-0.28 D_{t-1}^{+} s_{t-1}+v_{t} \\
& (5.44) \quad(2.20)
\end{aligned}
$$

Chi-Squared (3) $=20.09$ with significance level 0.00016

$$
\begin{aligned}
& \log h_{t}=\underset{(-3.02)}{-0.82+0.21 \mid}\left|\varepsilon_{t-1}\right| / \sqrt{h_{t-1}}+0.90 \log h_{t-1}-0.11 \varepsilon_{t-1} / \sqrt{h_{t-1}} . \\
& \text { aic }=-2658.68 \text { bic }=-2635.62
\end{aligned}
$$


Table 3 - Long-run Equilibrium for Positive and Negative Shocks

\begin{tabular}{|c|c|c|c|c|c|c|}
\hline & Lags & $\begin{array}{l}\text { Long-run } \\
\text { Equilibrium }\end{array}$ & $\begin{array}{c}\text { High } \\
\text { Uncertainty } \\
\text { Regime } \\
\text { Equilibrium }\end{array}$ & $\begin{array}{c}\text { Low } \\
\text { Uncertainty } \\
\text { Regime } \\
\text { Equilibrium }\end{array}$ & $\begin{array}{c}\text { Difference } \\
\text { Between High } \\
\text { and Long-run } \\
\text { Equilibrium }\end{array}$ & $\begin{array}{c}\text { Difference } \\
\text { Between Low } \\
\text { and Long-run } \\
\text { Equilibrium }\end{array}$ \\
\hline \multicolumn{7}{|l|}{ Linear Models } \\
\hline Industrial Production & 2 & 0.0025 & & & & \\
\hline Durable Goods & 1 & 0.00266 & & & & \\
\hline Employment & 3 & 0.0014 & & & & \\
\hline Consumer Credit & 3 & 0.00633 & & & & \\
\hline Bank Loans & 5 & 0.0062 & & & & \\
\hline Bank Cash & 1 & 0.00632 & & & & \\
\hline \multicolumn{7}{|l|}{ LSTAR Models } \\
\hline S\&P Var - Ind. Prod. & & & -0.0054 & 0.00417 & -0.0079 & 0.00167 \\
\hline S\&P Var - CC & & & 0.0016 & 0.00795 & -0.00473 & 0.00162 \\
\hline S\&P Var - Emp. & & & 0.00 & 0.0021 & -0.0014 & 0.0007 \\
\hline BOS - Ind. Prod. & & & -0.0015 & 0.0043 & -0.004 & 0.0018 \\
\hline BOS - Durables & & & -0.0187 & 0.0087 & -0.02136 & 0.00604 \\
\hline BOS - CC & & & 0.0054 & 0.0075 & -0.00093 & 0.00117 \\
\hline Index - Ind. Prod. & & & 0.00 & 0.0028 & -0.0025 & 0.0003 \\
\hline Index - Loans & & & 0.00 & 0.0083 & -0.0062 & 0.0021 \\
\hline Index - CC & & & 0.00105 & 0.0072 & -0.00528 & 0.00087 \\
\hline Int. Spread - Cash & & & 0.1137 & 0.00397 & 0.10738 & -0.00235 \\
\hline
\end{tabular}

Note: The number of lags for the linear models is selected by minimizing the BIC. Each of the equilibriums for the LSTAR models are obtained from the coefficient estimates in Table 4. The numbers in bold indicate whether the absolute value of the difference between the high uncertainty equilibrium and long-run equilibrium or the difference between the low uncertainty equilibrium and the long-run equilibrium is greater. 
Table 4 - Alternate Measures of Uncertainty and Other Important Macroeconomic Variables

$$
y_{t}=\alpha_{0}+\alpha_{1} y_{t-1}+\left(\beta_{0}+\beta_{1} y_{t-1}\right)\left[1+\exp \left(-\gamma\left(u_{t}-c\right)\right)\right]^{-1}+\varepsilon_{t}
$$

\begin{tabular}{|c|c|c|c|c|c|c|c|c|c|c|}
\hline $\begin{array}{l}\text { Uncertainty } \\
\text { Measure }\end{array}$ & $\begin{array}{l}\text { S\&P } 500 \\
\text { Variance }\end{array}$ & $\begin{array}{l}\text { S\&P } 500 \\
\text { Variance }\end{array}$ & $\begin{array}{l}\text { S\&P } 500 \\
\text { Variance }\end{array}$ & $\begin{array}{l}\text { BOS } \\
\text { Data }\end{array}$ & $\begin{array}{l}\text { BOS } \\
\text { Data }\end{array}$ & $\begin{array}{l}\text { BOS } \\
\text { Data }\end{array}$ & $\begin{array}{l}\text { Uncertainty } \\
\text { Index }\end{array}$ & $\begin{array}{l}\text { Uncertainty } \\
\text { Index }\end{array}$ & $\begin{array}{l}\text { Uncertainty } \\
\text { Index }\end{array}$ & $\begin{array}{c}\text { Interest Rate } \\
\text { Spread }\end{array}$ \\
\hline $\begin{array}{c}\text { Economic } \\
\text { Activity Measure }\end{array}$ & $\begin{array}{c}\text { Industrial } \\
\text { Production }\end{array}$ & $\begin{array}{c}\text { Consumer } \\
\text { Credit }\end{array}$ & Employment & $\begin{array}{c}\text { Industrial } \\
\text { Production }\end{array}$ & $\begin{array}{l}\text { Durable } \\
\text { Goods }\end{array}$ & $\begin{array}{c}\text { Consumer } \\
\text { Credit }\end{array}$ & $\begin{array}{l}\text { Industrial } \\
\text { Production }\end{array}$ & $\begin{array}{l}\text { Bank } \\
\text { Loans }\end{array}$ & $\begin{array}{l}\text { Consumer } \\
\text { Credit }\end{array}$ & Bank Cash \\
\hline$\alpha_{0}$ & $0.003 * * *$ & $0.0031 * * *$ & $0.0016 * * *$ & $0.003 * * *$ & $0.008 * * *$ & $0.0059 * * *$ & $0.003 * * *$ & 0.001 & $0.0015 * * *$ & $0.004 * *$ \\
\hline$\alpha_{1}$ & $0.28 * * *$ & $0.61 * * *$ & $0.25^{* * *}$ & $0.31 * * *$ & 0.08 & $0.195^{*}$ & -0.07 & $0.88 * * *$ & $0.71 * * *$ & -0.007 \\
\hline$\beta_{0}$ & $-0.005 * * *$ & $-0.0026^{* *}$ & $-0.0016^{* * *}$ & $-0.004 * *$ & -0.028 & $-0.0044 * * *$ & $-0.003 * * *$ & -0.001 & -0.0011 & $0.04 *$ \\
\hline$\beta_{1}$ & $0.35 * * *$ & 0.08 & $0.55^{* * *} *$ & 0.03 & -0.15 & $0.53 * * *$ & $0.45^{* * *}$ & -0.26 & -0.09 & $0.62 * * *$ \\
\hline$\gamma^{1}$ & 5889 & 3097 & 606899 & 38.6 & 14.6 & 2620 & 13.04 & 19.35 & 10.38 & 8.17 \\
\hline$c^{2}$ & 0.00225 & 0.0022 & 0.0018 & 0.736 & 0.8 & 0.515 & 115 & 156 & 152 & 3.96 \\
\hline
\end{tabular}

Note: The table reports estimates for each parameter in the LSTAR model.

* Denotes statistical significance at the $90 \%$ level.

** Denotes statistical significance at the $95 \%$ level.

*** Denotes statistical significance at the $99 \%$ level.

${ }^{1}$ The parameters are undefined when $\gamma=0$. Therefore, significance levels for the null hypothesis $\gamma=0$ are not reported.

${ }^{2}$ Also significance levels for $\mathrm{c}=0$ are not reported since our uncertainty variables are always positive. 
Figure 1 - Uncertainty and Industrial Production

Panel A: Conditional variance of the S\&P 500 along with monthly U.S. industrial production

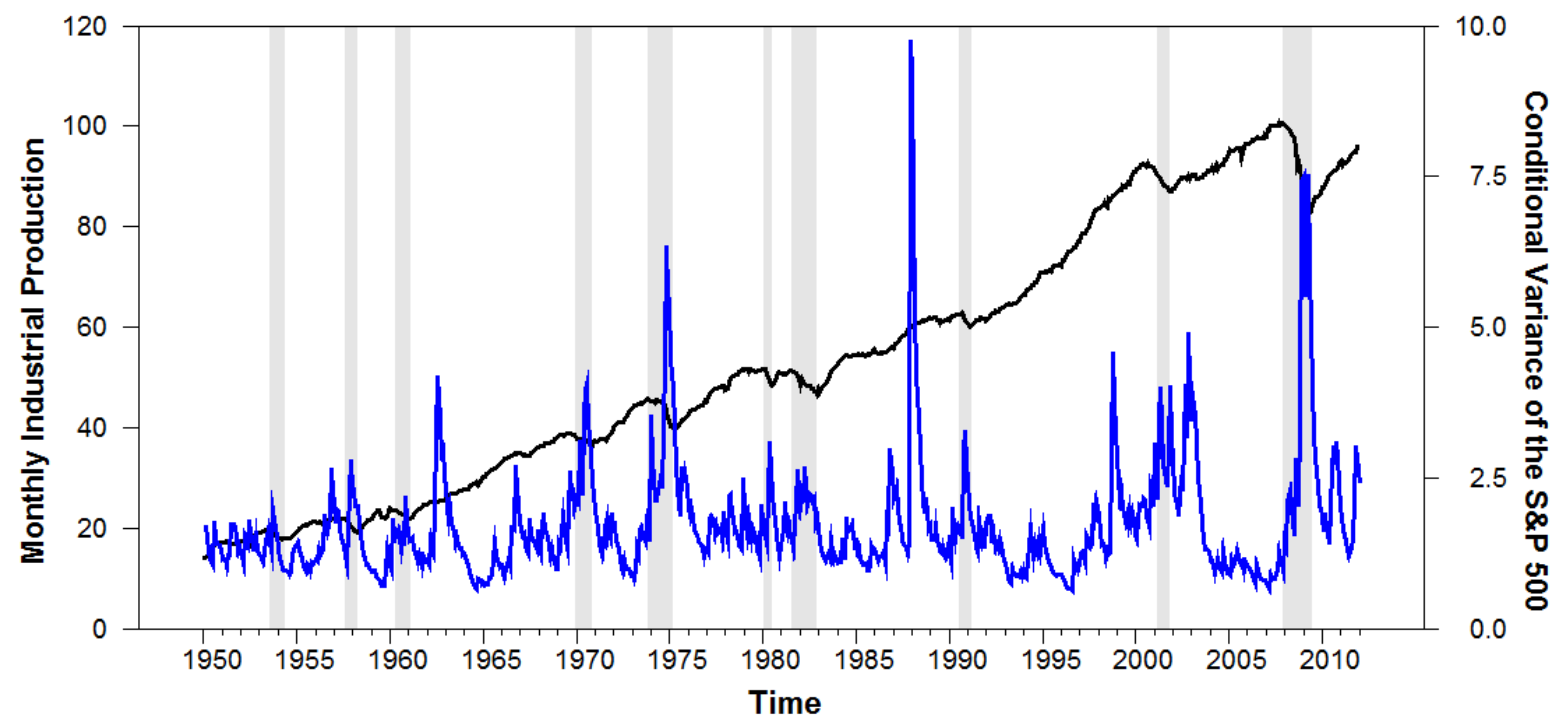

Panel B: Values of theta in the LSTAR model

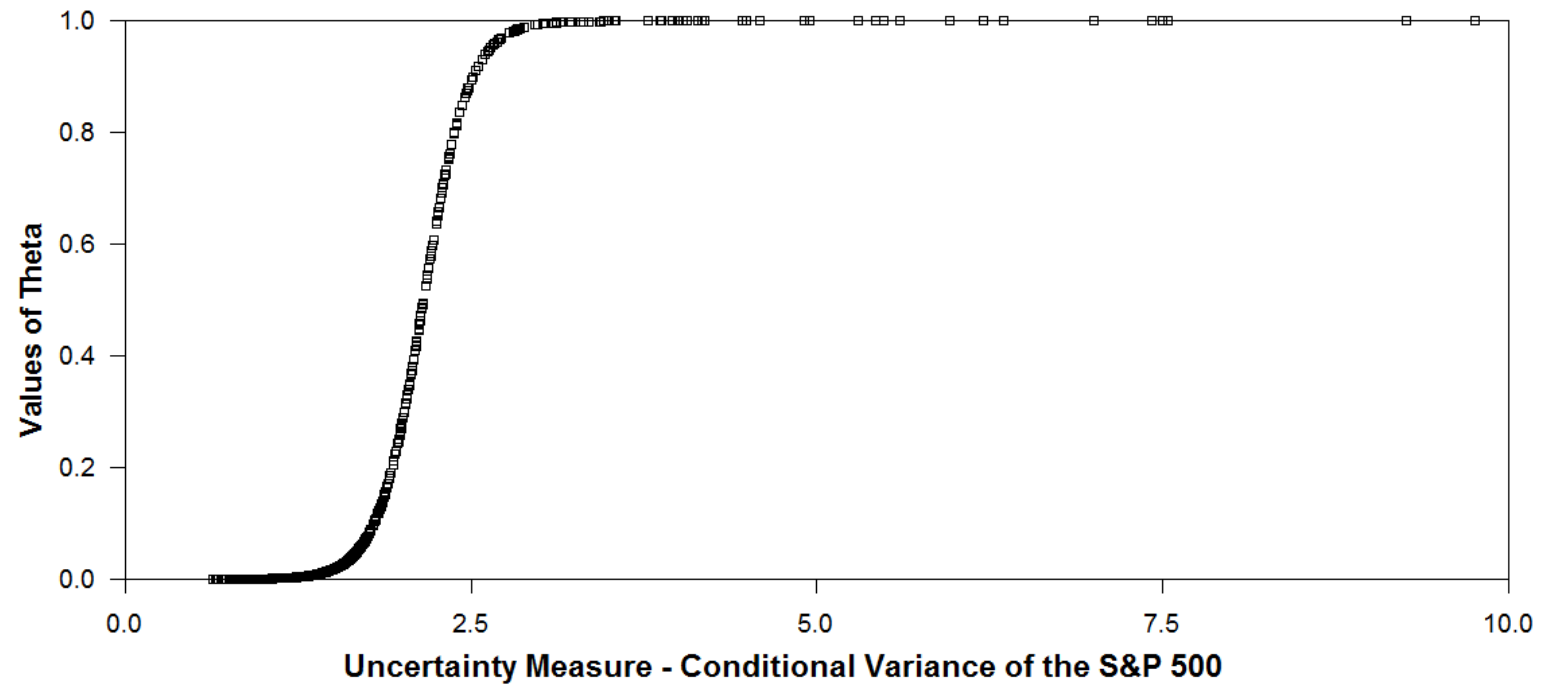

Note: Figure 1 shows the conditional variance estimated by an $\operatorname{EGARCH}(1,1)$ model normalized by dividing by the standard deviation of the series. Panel B shows values of theta in the LSTAR model where $\theta=\left[1+\exp \left(-6.146\left(h_{t}-2.155\right)\right)\right]^{-1}$. 
Figure 2 - Historical Decompositions and Permanent Uncertainty Shocks

Panel A: Decomposition if uncertainty equals its average value during the 1990s

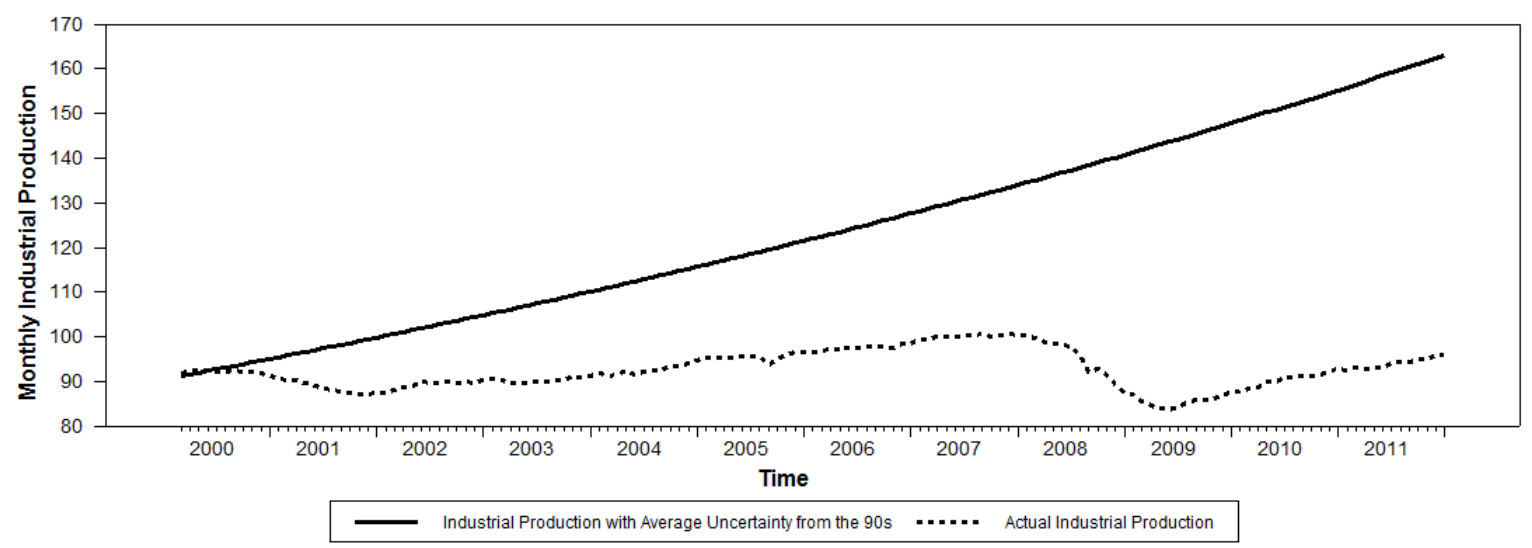

Panel B: Decomposition if uncertainty equals its average value during the financial crisis

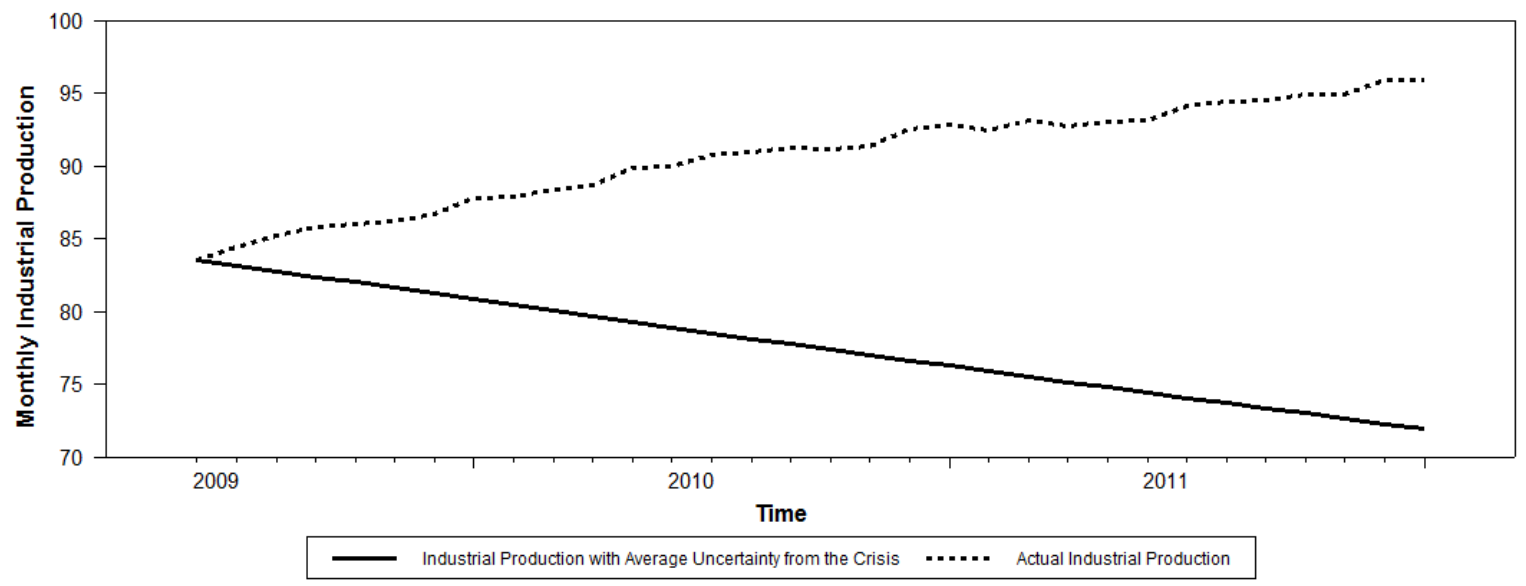

Panel C: Effects of permanent shocks to uncertainty

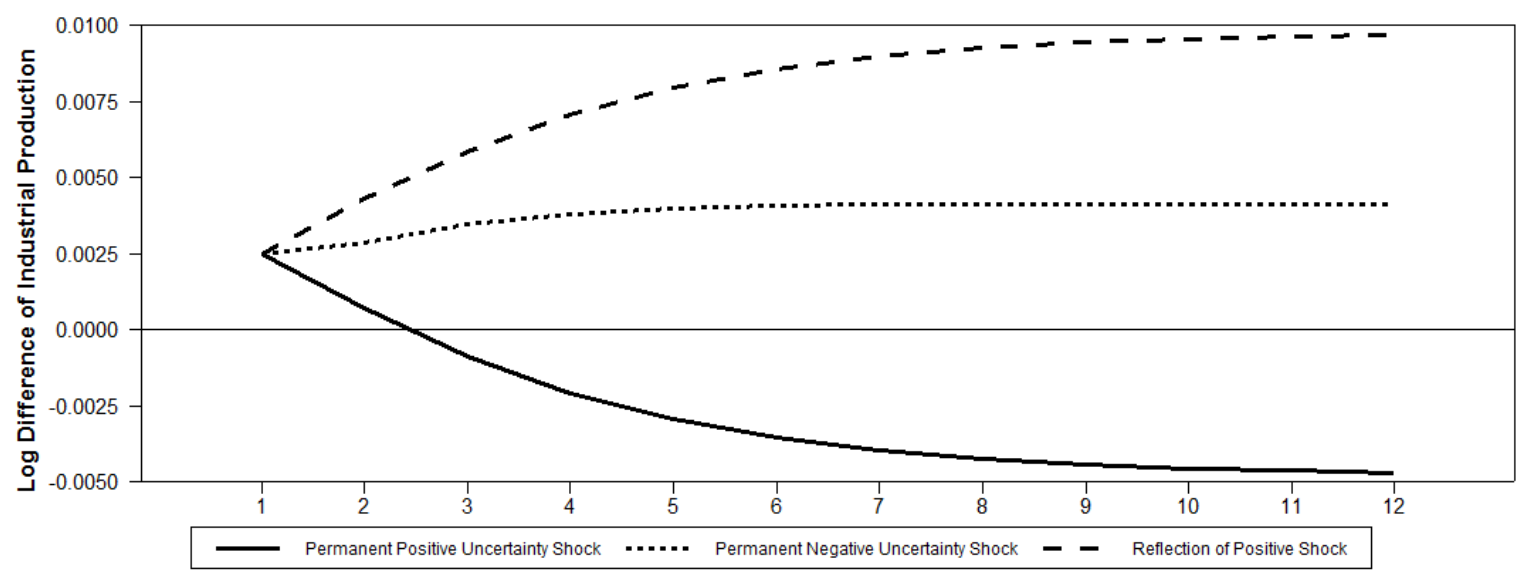

Note: Figure 2 Panel $\mathrm{C}$ shows the asymmetric effects of a permanent positive and a permanent negative uncertainty shock. The reflection of the positive shock shows that positive shocks have greater effects than negative shocks. 
Figure 3 - Impulse Responses to a Temporary Positive Uncertainty Shock

Panel A: Impulse response to a positive one-standard-deviation uncertainty shock occurring in 2008:12

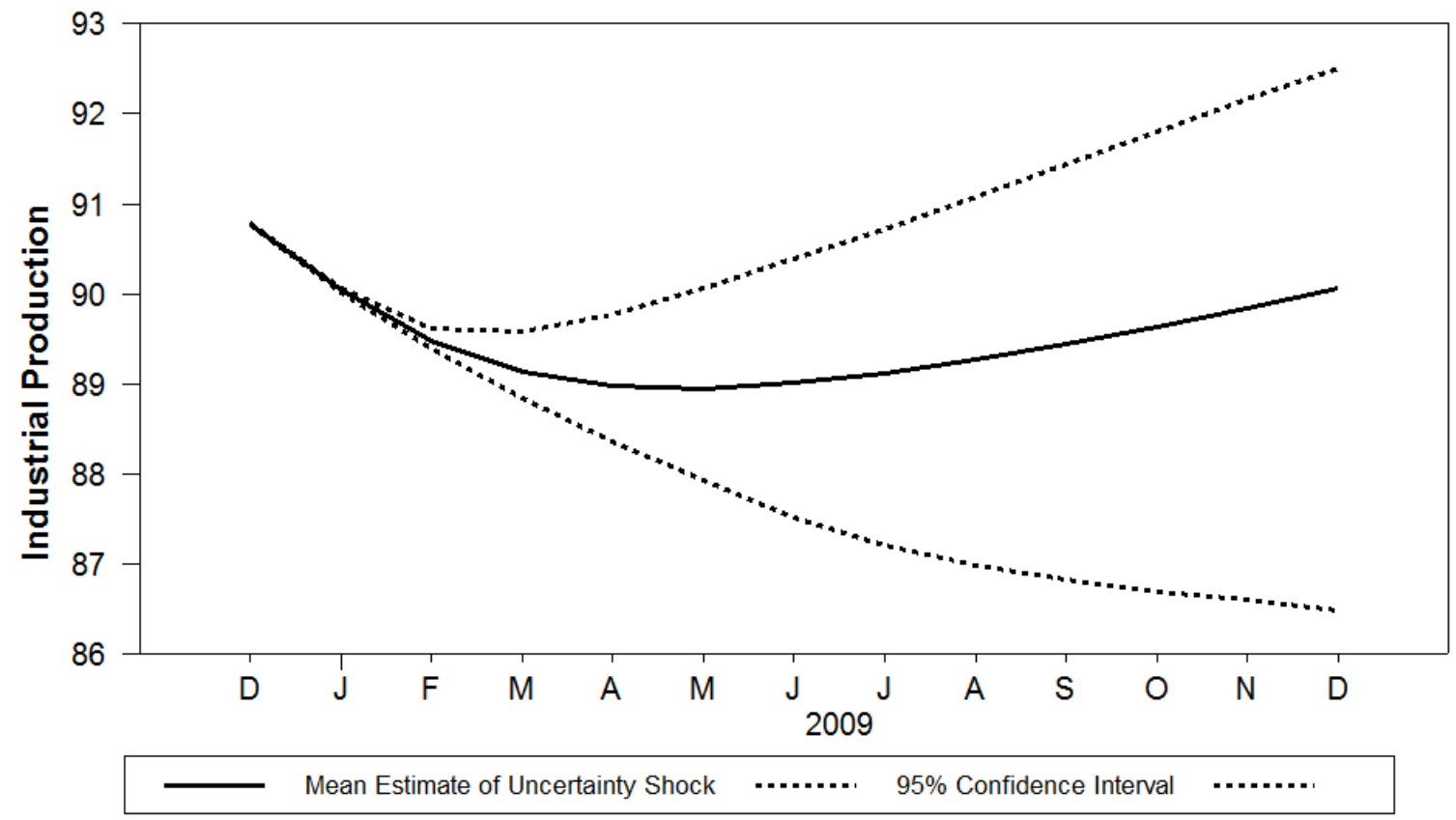

Panel B: Impulse response to a 2008:12 uncertainty shock occurring in 2008:1

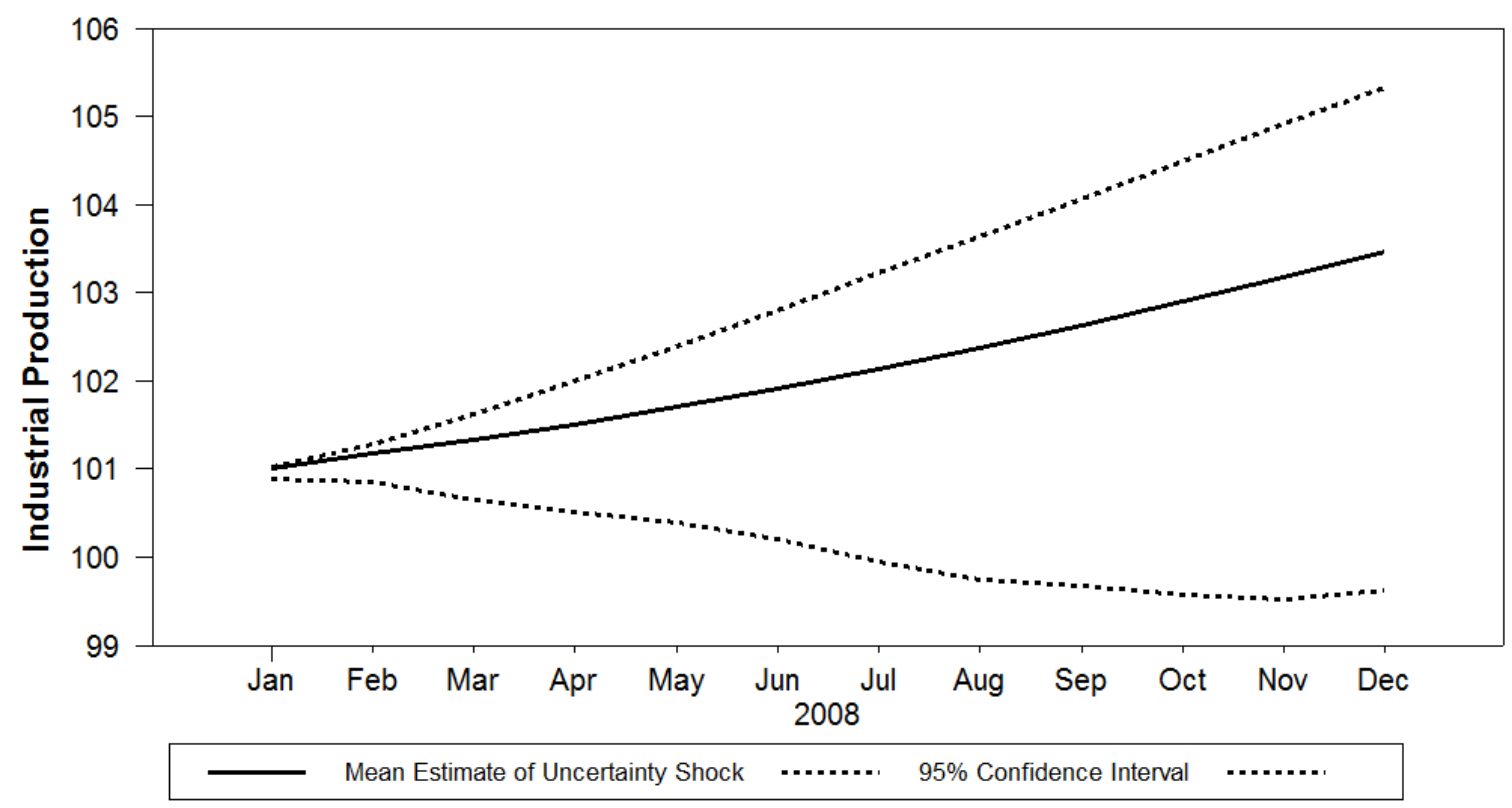


Figure 4 - The Asymmetric Effects of Temporary Uncertainty Shocks

Panel A: Impulse responses to uncertainty shocks during the financial crisis (2008:12)

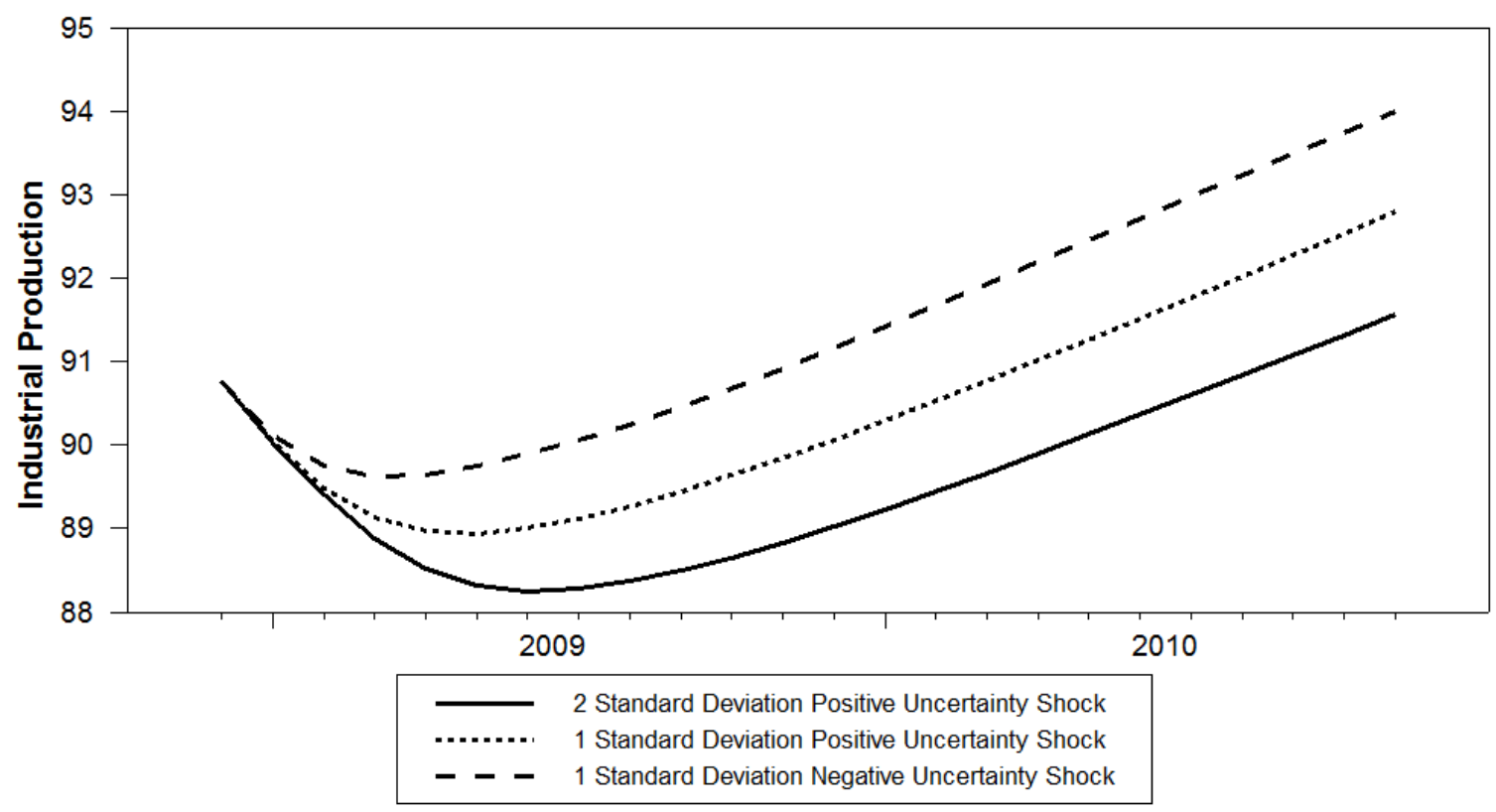

Panel B: Impulse responses to uncertainty shocks before the financial crisis (2008:1)

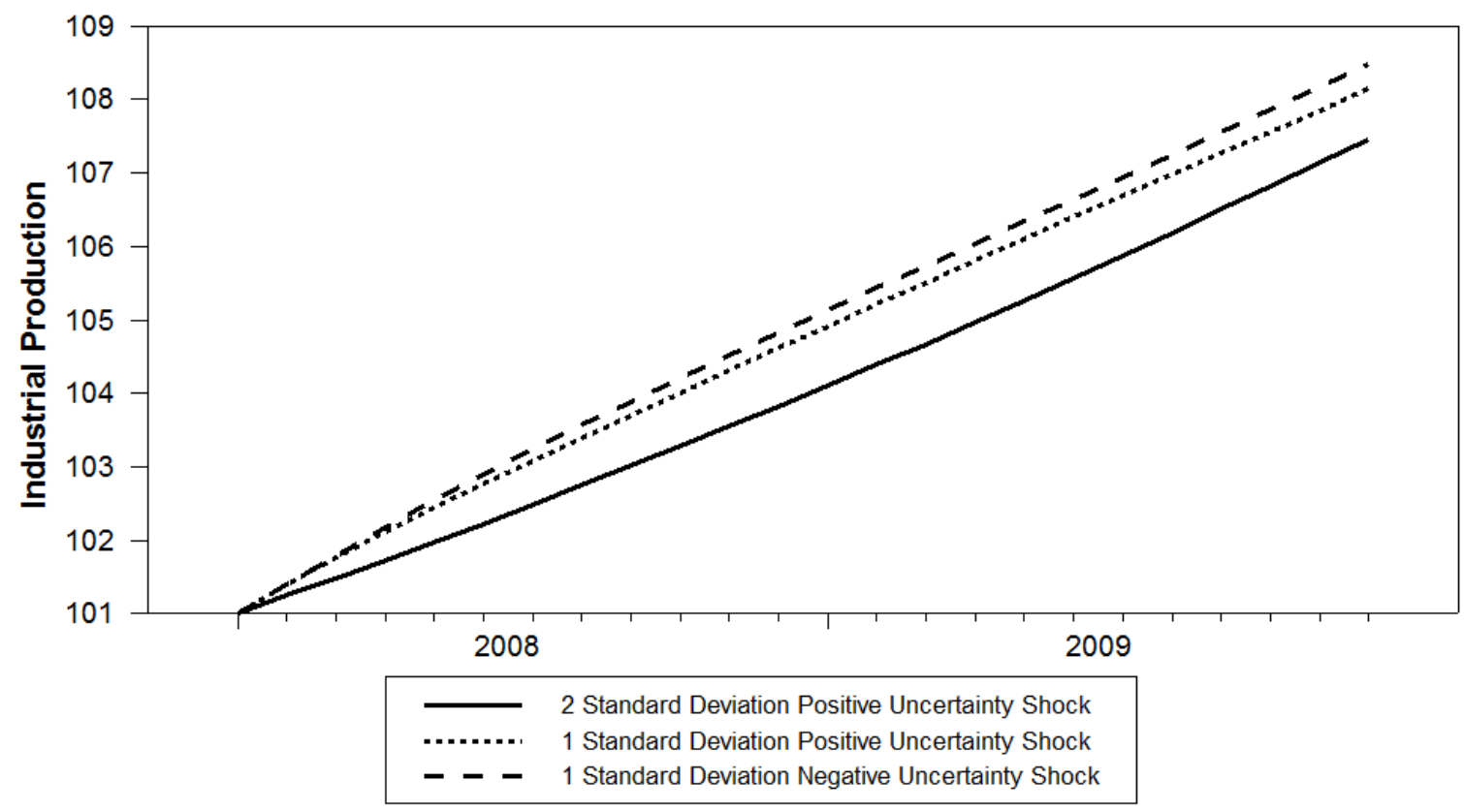

Note: Figure 4 shows the impulse responses to a temporary positive one-standard-deviation uncertainty shock, a temporary positive two-standard-deviation uncertainty shock, and a temporary negative onestandard-deviation uncertainty shock before and during the financial crisis. All lines show mean estimates of each impulse response. 
Figure 5 - Values of Theta in the Nonlinear VAR Model

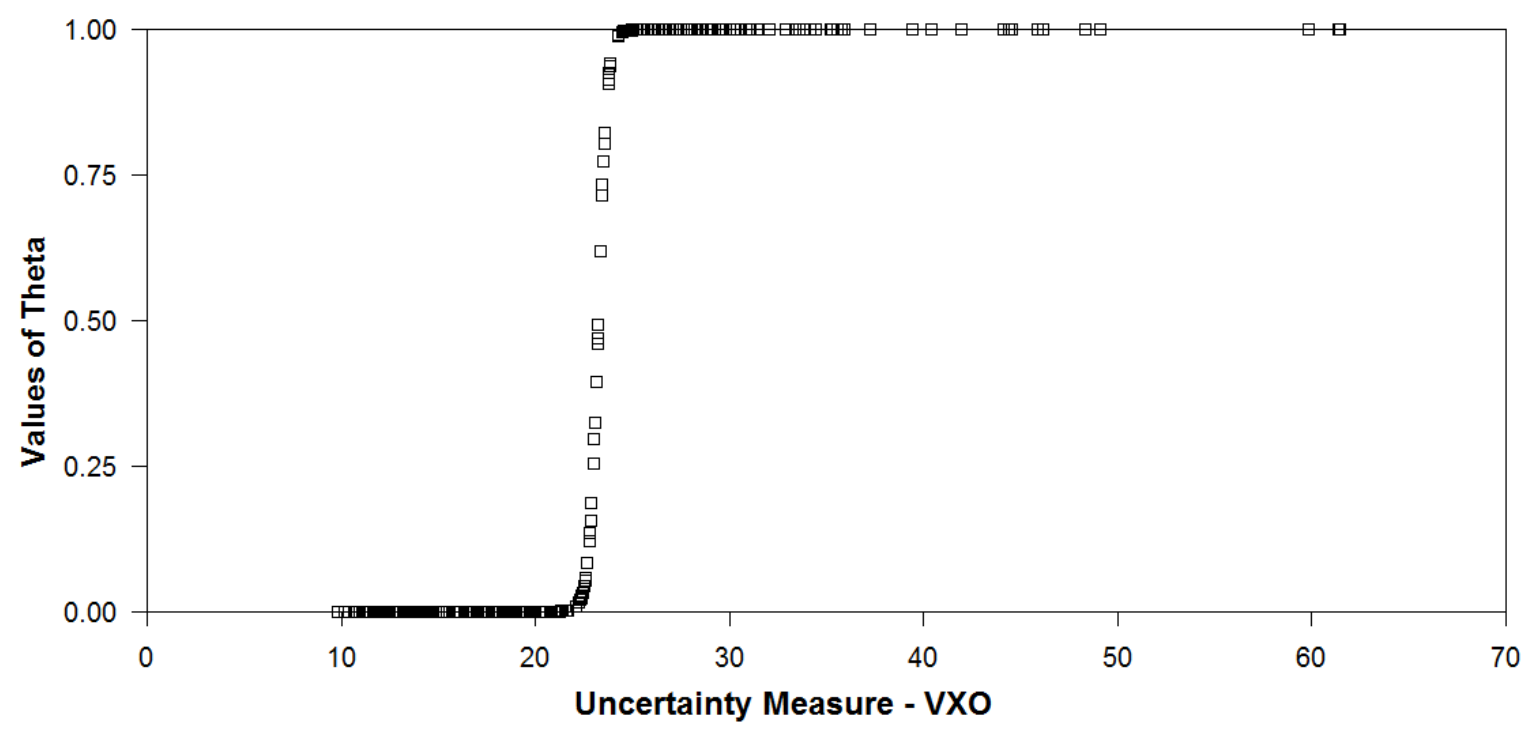

Note: The uncertainty measure in the nonlinear VAR is the implied volatility based on the Chicago Board of Options Exchange VXO index. The value of theta in the LSTAR model is defined as $\theta=\left[1+\exp \left(-4.36\left(\text { vxo }_{t-1}-23.23\right)\right)\right]^{-1}$. 
Figure 6 - Uncertainty and Consumer Credit

Panel A: Conditional variance of the S\&P 500 and monthly U.S. consumer credit

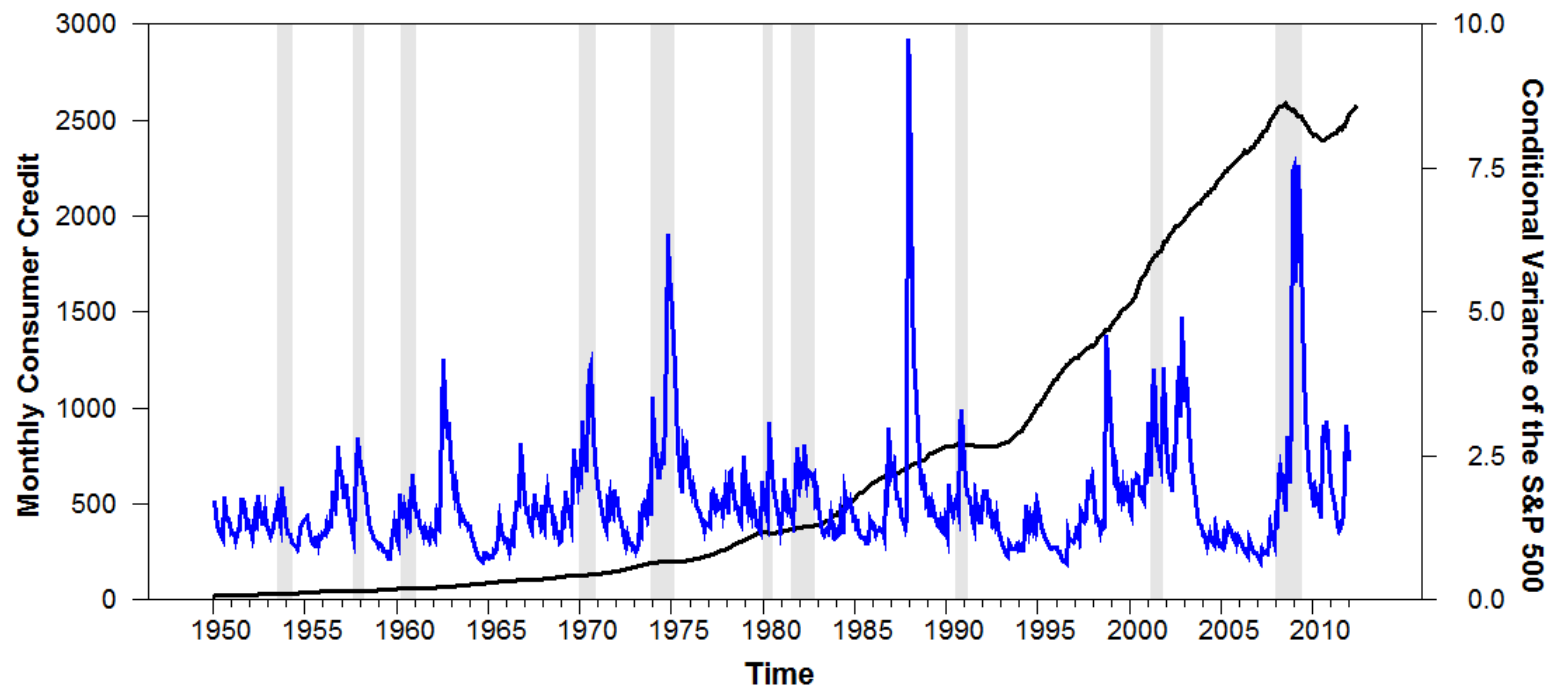

Panel B: Values of theta in the LSTAR model

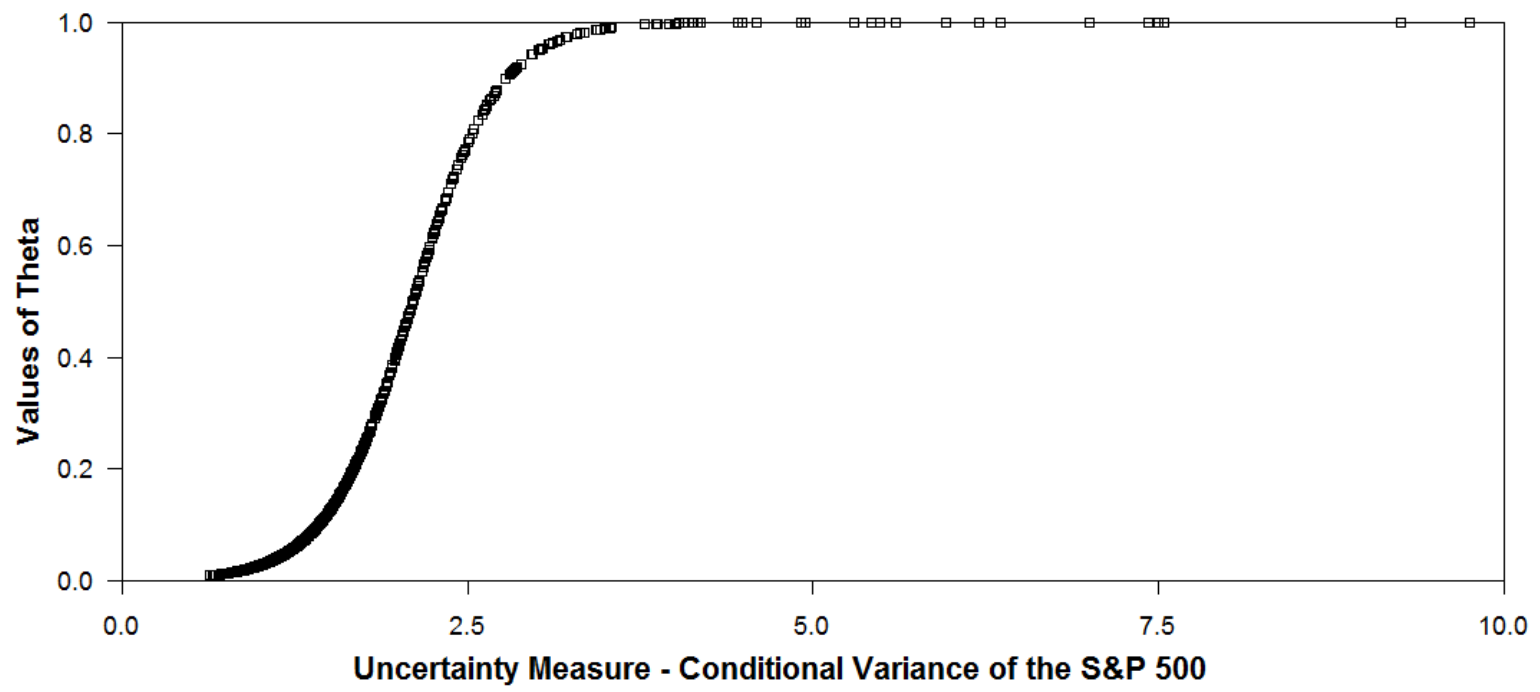

Note: Figure 6 shows the conditional variance estimated by an $\operatorname{EGARCH}(1,1)$ model normalized by dividing by the standard deviation of the series. Panel B shows values of theta in the LSTAR model where $\theta=\left[1+\exp \left(-3.23\left(h_{t}-2.103\right)\right)\right]^{-1}$. 
Figure 7 - Historical Decompositions and Permanent Uncertainty Shocks

Panel A: Decomposition if uncertainty equals its average value during the 1990s

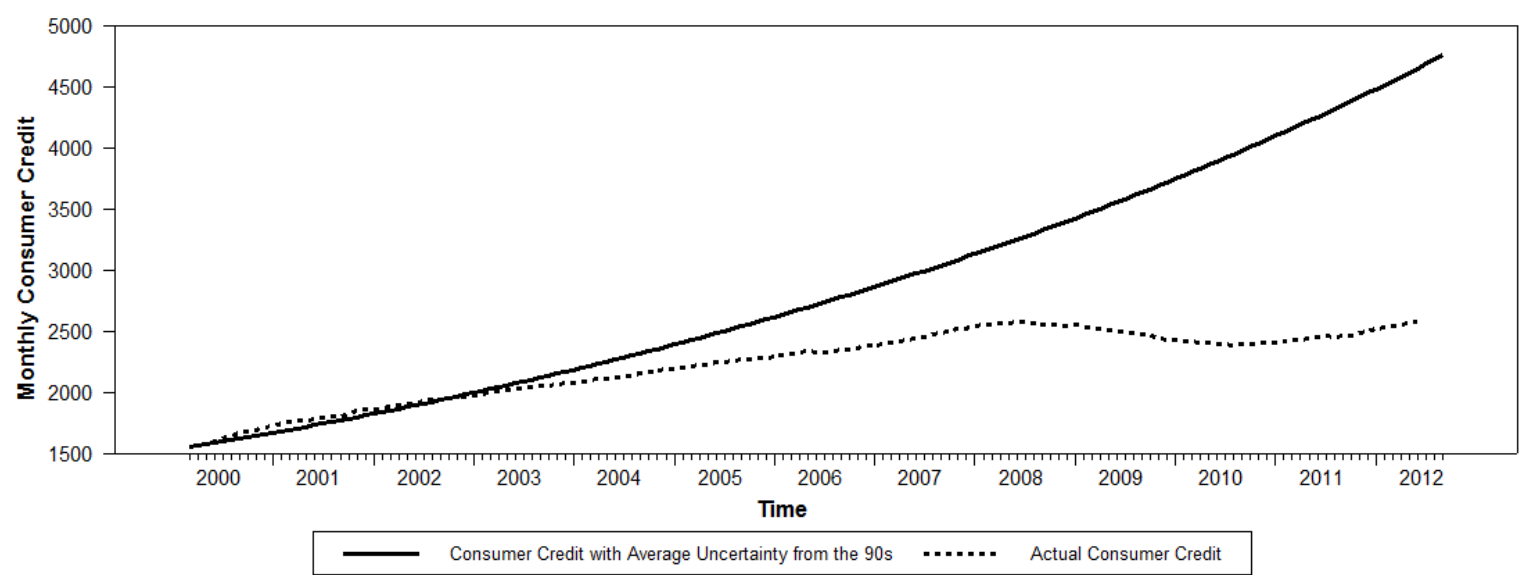

Panel B: Decomposition if uncertainty equals its average value during the financial crisis

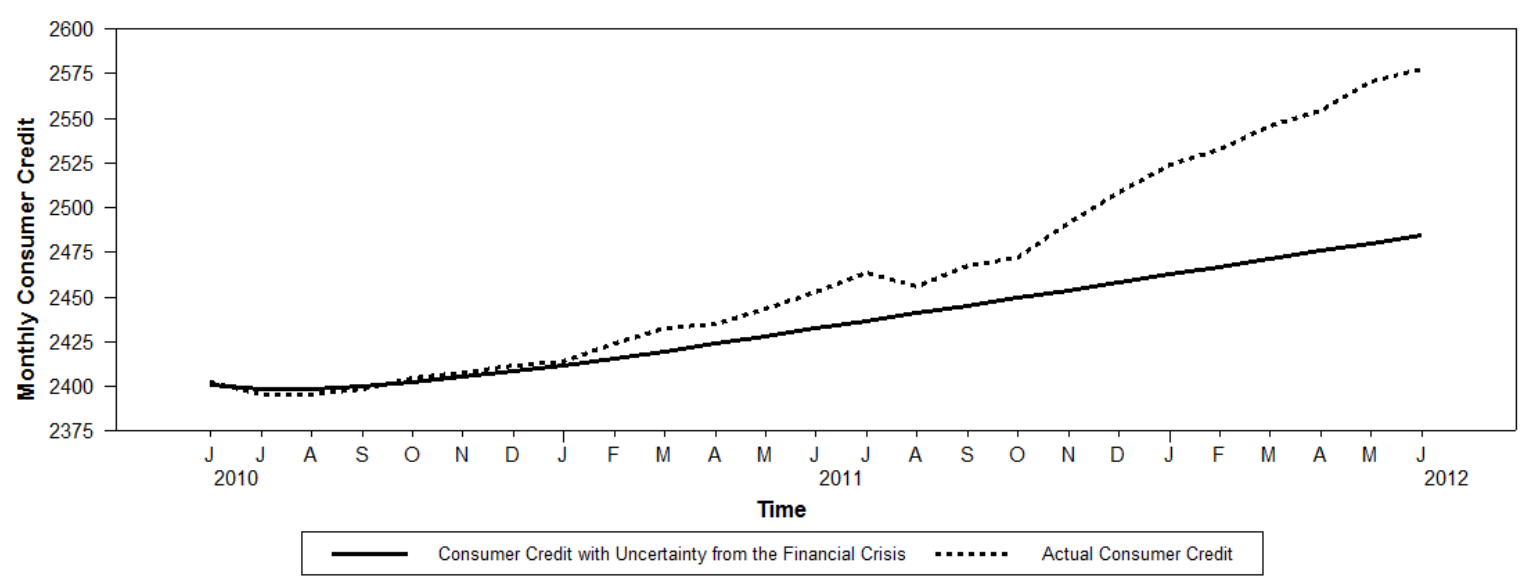

Panel C: Effects of permanent shocks to uncertainty

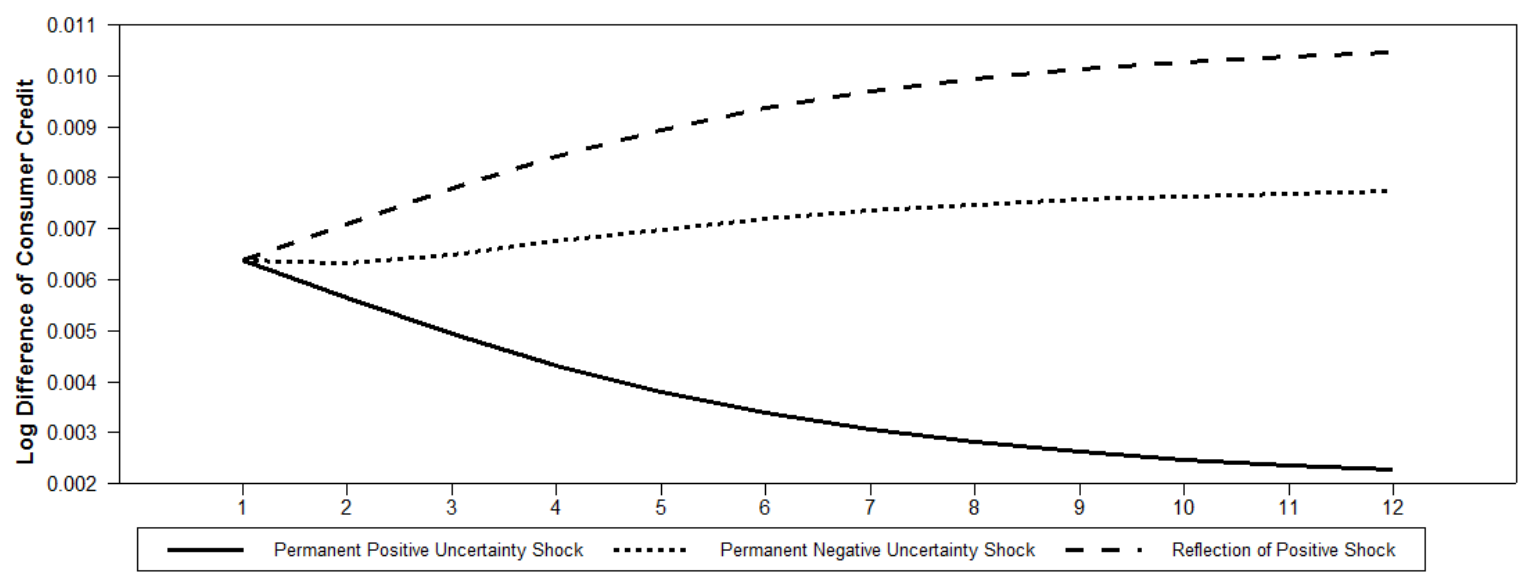

Note: Panel C shows the asymmetric effects of a permanent positive and negative uncertainty shock. The reflection of the positive shock shows that positive shocks have greater effects than negative shocks. 
Figure 8 - The Assymetric Effects of Temporary Uncertainty Shocks

Panel A: Impulse responses to uncertainty shocks during the financial crisis (2008:12)

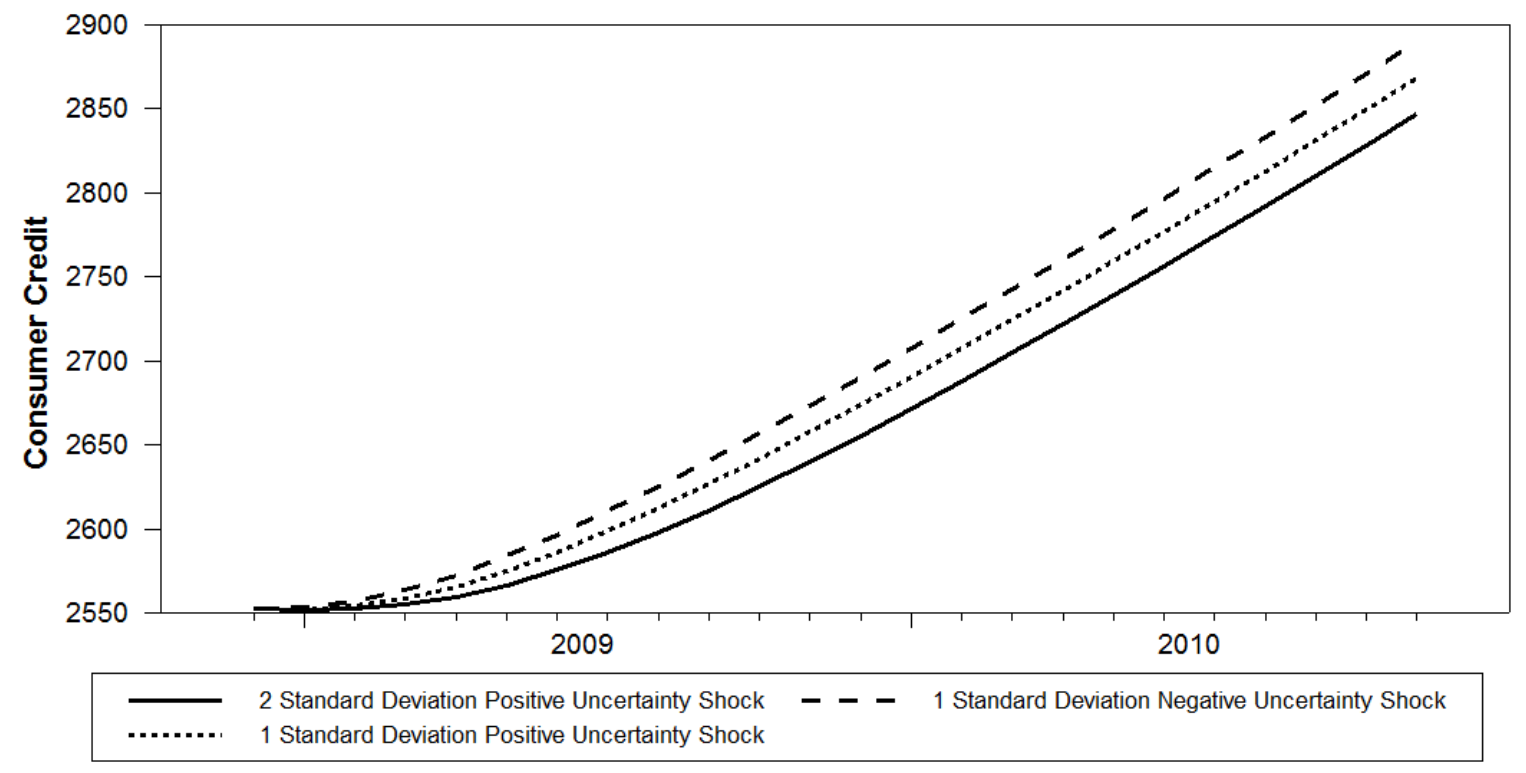

Panel B: Impulse responses to uncertainty shocks before the financial crisis (2008:1)

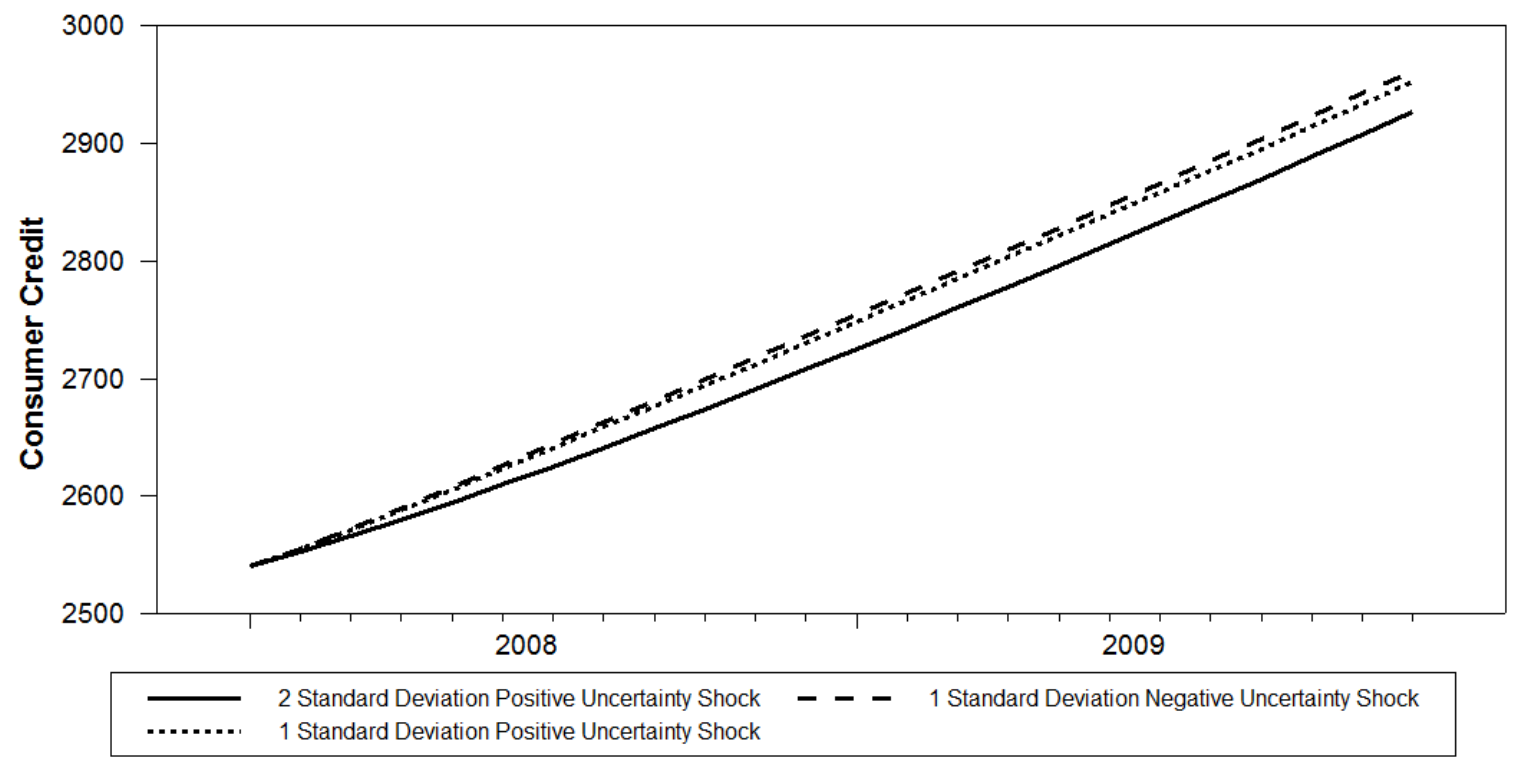

Note: Figure 8 shows the impulse responses to a temporary positive one-standard-deviation uncertainty shock, a temporary positive two-standard-deviation uncertainty shock, and a temporary negative onestandard-deviation uncertainty shock before and during the financial crisis. All lines show mean estimates of each impulse response. 